\title{
Advanced Design and Synthesis of Composite Photocatalysts for the Remediation of Wastewater: A Review
}

\author{
Jianlong Ge, Yifan Zhang, Young-Jung Heo and Soo-Jin Park* \\ Department of Chemistry and Chemical Engineering, Inha University, 100 Inharo, Incheon 22212, Korea; \\ gejianlong1121@126.com (J.G.); zyf910626@inhaian.net (Y.Z.); heoyj1211@inhaian.net (Y.-J.H.) \\ * Correspondence: sjpark@inha.ac.kr; Tel.: +82-32-860-7234; Fax: +82-32-860-5604
}

Received: 29 December 2018; Accepted: 28 January 2019; Published: 30 January 2019

\begin{abstract}
Serious water pollution and the exhausting of fossil resources have become worldwide urgent issues yet to be solved. Solar energy driving photocatalysis processes based on semiconductor catalysts is considered to be the most promising technique for the remediation of wastewater. However, the relatively low photocatalytic efficiency remains a critical limitation for the practical use of the photocatalysts. To solve this problem, numerous strategies have been developed for the preparation of advanced photocatalysts. Particularly, incorporating a semiconductor with various functional components from atoms to individual semiconductors or metals to form a composite catalyst have become a facile approach for the design of high-efficiency catalysts. Herein, the recent progress in the development of novel photocatalysts for wastewater treatment via various methods in the sight of composite techniques are systematically discussed. Moreover, a brief summary of the current challenges and an outlook for the development of composite photocatalysts in the area of wastewater treatment are provided.
\end{abstract}

Keywords: Composite catalysts; photocatalysis; synergy effect; solar energy; wastewater remediation

\section{Introduction}

In the past several decades, with the booming of industry, the ever-increasing consumption of natural resources, especially fresh water and fossil resources, have caused alarming damage to the environment and seriously threaten the sustainability of human society [1-3]. As a worldwide concern, freshwater pollution drives people to seek for an effective approach to repair the polluted water environment. In general, the contaminants in water are mainly derived from the sewage effluent of industries (e.g., textile industry, paper industry, the pharmaceutical industry, etc.), and domestic contaminants (e.g., pharmaceuticals, pesticide, detergent, etc.) [4]. Until now, numerous contaminants have been detected and are classified as inorganic ions, organic chemicals, and pathogens; most of those contaminants are toxic to organisms [4-7]. Up to now, a variety of strategies including chemical or physical coagulation [8], sedimentation [9], adsorption [10], membrane filtration [11], and biological degradation method [12] have been invented to treat wastewater. However, due to the complex compositions and different physico-chemical properties of the contaminants, there are still several limitations of these traditional techniques, such as the low efficiency, high energy consumption, and the risk of secondary pollution [13-15]. Consequently, a promoted technique with high efficiency, low energy consumption, and being environmentally friendly is highly desired for the remediation of wastewater.

Nowadays, the advanced oxidation processes (AOPs) have been extensively explored to remove the non-biodegradable and highly stable compounds in water $[16,17]$. In fact, the AOPs are chemical 
processes that can generate highly reactive hydroxyl radicals $(\cdot \mathrm{OH})$ in situ. The $\cdot \mathrm{OH}$ in water exhibits an extremely strong oxidizing property with a high oxidation potential of $2.80 \mathrm{~V} / \mathrm{SHE}\left(\cdot \mathrm{OH} / \mathrm{H}_{2} \mathrm{O}\right)$, such that it can non-selectively oxidize the contaminants and finally convert them to $\mathrm{CO}_{2}, \mathrm{H}_{2} \mathrm{O}$, or small inorganic ions in a short time $[17,18]$. In most cases, the $\cdot \mathrm{OH}$ could be produced with the presence of one or more primary oxidants, and/or energy sources or catalysts. Therefore, the typical AOPs could be classified as Fenton reactions, the electrochemical advanced oxidation processes, and the heterogeneous photocatalysis [17]. Compared with the traditional water remediation techniques, the AOPs exhibit many advantages, which include: (1) the contaminants are directly destroyed or reduced in the water body, rather than simply coagulated or filtrated from the water, thus the secondary pollution could be avoided; (2) the AOPs are suitable for a wide range of contaminants including some inorganics and pathogens because of their robust non-selectively oxidizability; and (3) no hazardous byproducts will be generated due to the final reduction products of the AOPs being just $\mathrm{CO}_{2}, \mathrm{H}_{2} \mathrm{O}$, or small inorganic ions. With the abovementioned merits, the AOPs have attracted significant attention from both scientific research and industrial processing [19].

Solar energy is a green, costless, and inexhaustible energy resource. Effective utilization of solar energy is of vital importance for enhancing the sustainability of industry, reducing pollution, and retarding global warming. Consequently, solar energy has been widely used in a range of applications, such as solar heating, photovoltaics, solar thermal energy, solar architecture, artificial photosynthesis, photocatalysis, etc. [20] Among which, photocatalysis is one of the most effective strategies for the AOPs, which just rely on the light radiation on the photocatalysts to drive the oxidization reaction at the ambient condition, and during the whole reaction process, no additional energy is needed and no toxic byproduct will be generated; therefore, it is a green chemical technique [21,22]. Actually, the core of photocatalytic AOPs are photocatalysts; semiconductors as the most employed heterogeneous photocatalysis for the AOPs have attained considerable development since Fujishima et al. [23] carried out the first photo-catalyzed AOP based on the titanium-oxide $\left(\mathrm{TiO}_{2}\right)$ in 1972. Up to now, a myriad of photocatalytic AOPs have been designed for water treatment based on various semiconductors. In general, semiconductors are light-sensitive because of their unique electronic structure with a filled valence band (VB) and an empty conduction band (CB) $[18,21]$. Figure 1 and Equations (1)-(6) demonstrate the basic reaction process of a semiconductor to generate the photocatalytic radicals, which could be decomposed in the following steps: (i) photons with a certain energy are absorbed by the semiconductor; (ii) the absorbed photons with energy greater than the band gap energy $\left(E_{b}\right)$ of semiconductors lead to the formation of electrons in the $C B$ and corresponding holes in the VB; and (iii) the generated electron-hole pairs will migrate to the surface of semiconductors for redox reactions, and fast recombination in nanoseconds will happen at the same time (it should be mentioned that this process is negative for the AOPs, which shall be suppressed [21,22]).

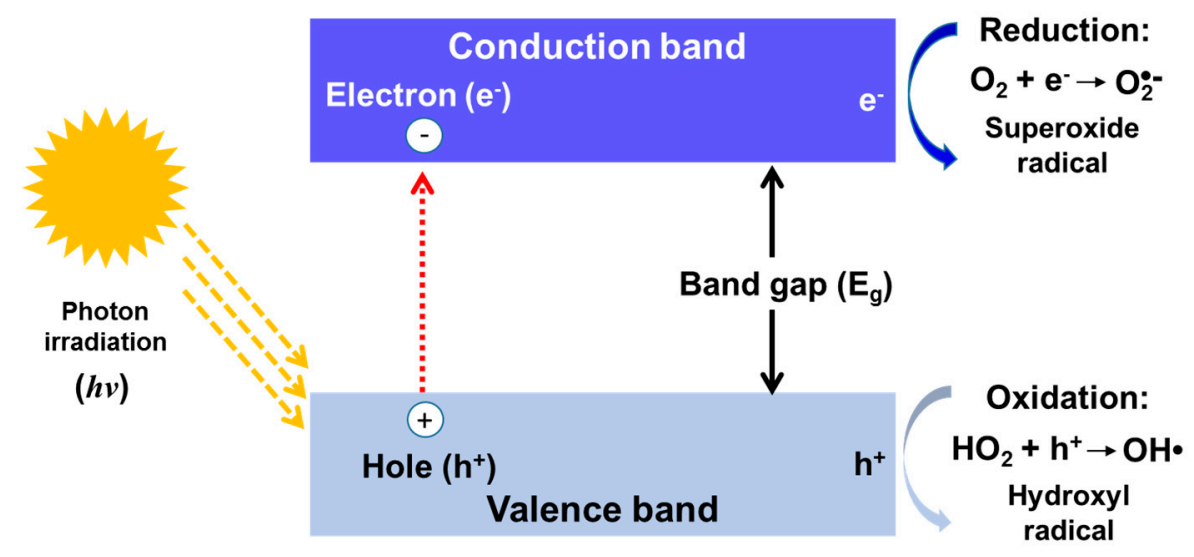

Figure 1. Schematic illustration of the photocatalytic reaction process of a semiconductor. Adapted with permission from Reference [18]. Copyright (2012) Elsevier. 
Excitation: Photon $(h v)+$ Semiconductor $\rightarrow \mathrm{e}^{-} \mathrm{CB}+\mathrm{h}^{+} \mathrm{VB}$

$$
\begin{gathered}
\text { Recombination: } \mathrm{e}^{-}+\mathrm{h}^{+} \rightarrow \text { energy } \\
\text { Oxidation of } \mathrm{H}_{2} \mathrm{O}: \mathrm{H}_{2} \mathrm{O}+\mathrm{h}^{+} \mathrm{VB} \rightarrow \bullet \mathrm{OH}+\mathrm{H}^{+} \\
\text {Reduction of adsorbed } \mathrm{O}_{2}: \mathrm{O}_{2}+\mathrm{e}^{-} \rightarrow \mathrm{O}_{2} \bullet \\
\text { Reaction with } \mathrm{H}^{+}: \mathrm{O}_{2} \bullet+\mathrm{H}^{+} \rightarrow \bullet \mathrm{OOH} \\
\text { Electrochemical reduction: } \bullet \mathrm{OOH}+\bullet \mathrm{OOH} \rightarrow \mathrm{H}_{2} \mathrm{O}_{2}+\mathrm{O}_{2}
\end{gathered}
$$

However, it remains a significant challenge to fabricate a high-efficiency visible light photocatalyst solely based on an individual semiconductor photocatalyst. For example, the $\mathrm{TiO}_{2}$, as the most used photocatalyst, possesses various advantages with excellent chemical stability, large surface area, non-toxicity, and low cost [24]; however, its wide energy band gap (3.0-3.2 eV) means it can only be excited by the UV light $(\lambda<400 \mathrm{~nm})$, such that less than $5 \%$ of the irradiated solar energy can be effectively used [25]. Moreover, the fast recombination speed of electron-hole pairs seriously limits the further improvement of its photocatalytic activity [18,22]. On the other hand, although the recently developed visible light response semiconductors have a lower energy band gap $(<3 \mathrm{eV})$, such as $\mathrm{BiOX}(\mathrm{X}=\mathrm{I}$ or $\mathrm{Br})$ [26], they still suffer from serious photo-corrosion problems in aqueous media via redox reactions and the fast recombination of electron-hole pairs during the reaction process. Therefore, it is highly urgent to find an effect strategy to further improve the performance of semiconductor photocatalysts.

From ancient times, people have recognized that the incorporation of two or more constituent materials could obtain various composite materials with intriguing properties superior to the individual components. Nowadays, a myriad of functional composite materials have been developed for different applications $[27,28]$. Actually, the enhanced performance of a composite material is mainly attributed to the synergistic effect of its individual constituent materials; meanwhile, this principle is also appropriate to the design of semiconductor photocatalysts. Up to now, there have been numerous pioneering studies reporting the design and fabrication of composite semiconductor photocatalysts via various methods, such as doping heteroatoms or constructing heterojunctions via directly compositing with individual semiconductors or carbonaceous nanomaterials, among others. Therefore, as shown in Scheme 1, in this review, we aim to provide a systematic appraisal of the recent development in the design and fabrication of various composite photocatalysts for the application of wastewater treatment. Meanwhile, some representative photocatalysts with composite structures and morphologies from the atomic scale to macroscopic scale are reviewed. Finally, the current developing status, challenges, and evolution trend of the composite semiconductor photocatalysts for wastewater remediation are briefly proposed.

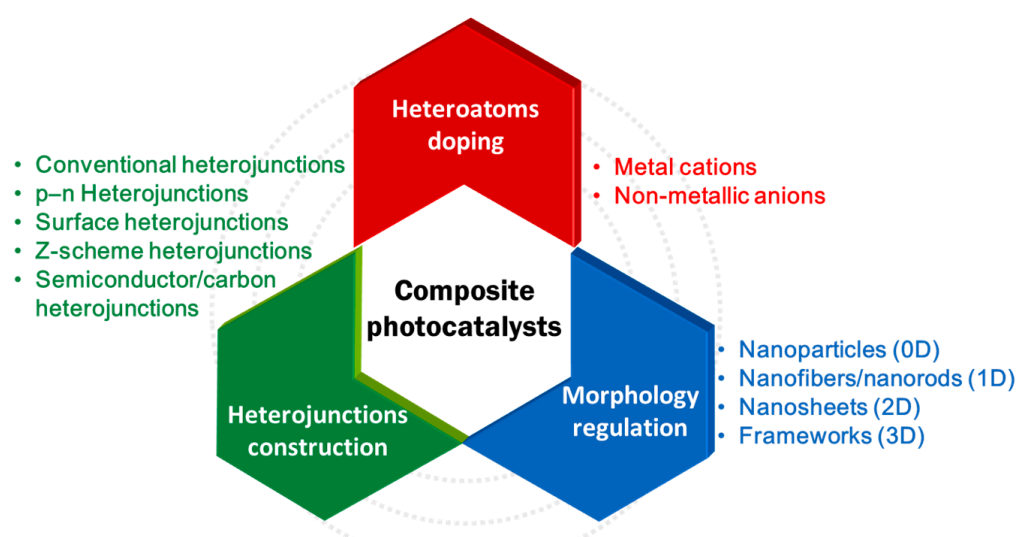

Scheme 1. The schematic illustration demonstrating the design and synthesis strategies for composite photocatalysts. 


\section{Principle of the Semiconductor Photocatalysts for Wastewater Remediation}

As mentioned above, the trace contaminants (e.g., phenol, chlorophenol, oxalic acid) derived from the dyeing industry, petrochemical industry, and the agricultural chemicals are quite difficult to remove from the water due to the low concentration and complex compositions [4]. A photocatalytic degradation method is considered as the most promising strategy to deal with this problem. According to the previous studies $[18,29,30]$, as shown in Figure 2, the basic mechanism of the photocatalytic degradation process of a contaminant could be characterized as the following steps: (i) the target contaminants transfer from the water body to the surface of the photocatalysts, in which the migration rate of corresponding contaminants may be influenced by the morphology and surface properties of the catalysts (e.g., surface area, porosity, and surface charges); (ii) the contaminants are adsorbed on the surface of catalysts with photon excited reaction sites, therefore a high surface area of the catalysts can provide more active sites for the reaction; (iii) the redox reactions of the photon activated sites with the adsorbed contaminants and the degraded intermediates are produced, which are finally degraded to $\mathrm{CO}_{2}$ and $\mathrm{H}_{2} \mathrm{O}$; (iv) part of the generated intermediates and the resultant mineralization products $\left(\mathrm{CO}_{2}\right.$ and $\left.\mathrm{H}_{2} \mathrm{O}\right)$ desorb from the surface of catalysts to expose the active sites for the subsequent reactions; and (v) the desorbed intermediates transfer from the interface of catalysts and water to the bulk liquid, and part of the intermediates will repeat the procedure $\mathrm{i}-\mathrm{v}$ until they are completely degraded to $\mathrm{CO}_{2}$ and $\mathrm{H}_{2} \mathrm{O}$. Based on the abovementioned principles of the semiconductor photocatalysts for water contaminants degradation, five main criteria for the design of an effective photocatalyst could be proposed as follow: (1) a semiconductor with a lower $E_{\mathrm{g}}$ is preferred so that the electron-hole pair could be excited easier; (2) the photon absorption capacity of the catalysts shall be as high as possible to generate more electron-hole pairs; (3) the recombination process of electron-hole pairs must be prevented as much as possible to enhance the quantum efficiency of the photo-generated electron-hole pairs; (4) the surface area of the catalysts shall be large to provide more reaction sites; and (5) the chemical and physical structures of photocatalysts must be stable and be beneficial for the mass transfer in water. To meet the abovementioned requirements, a variety of strategies have been developed for the design, some of the most-used strategies will be summarized in this review.

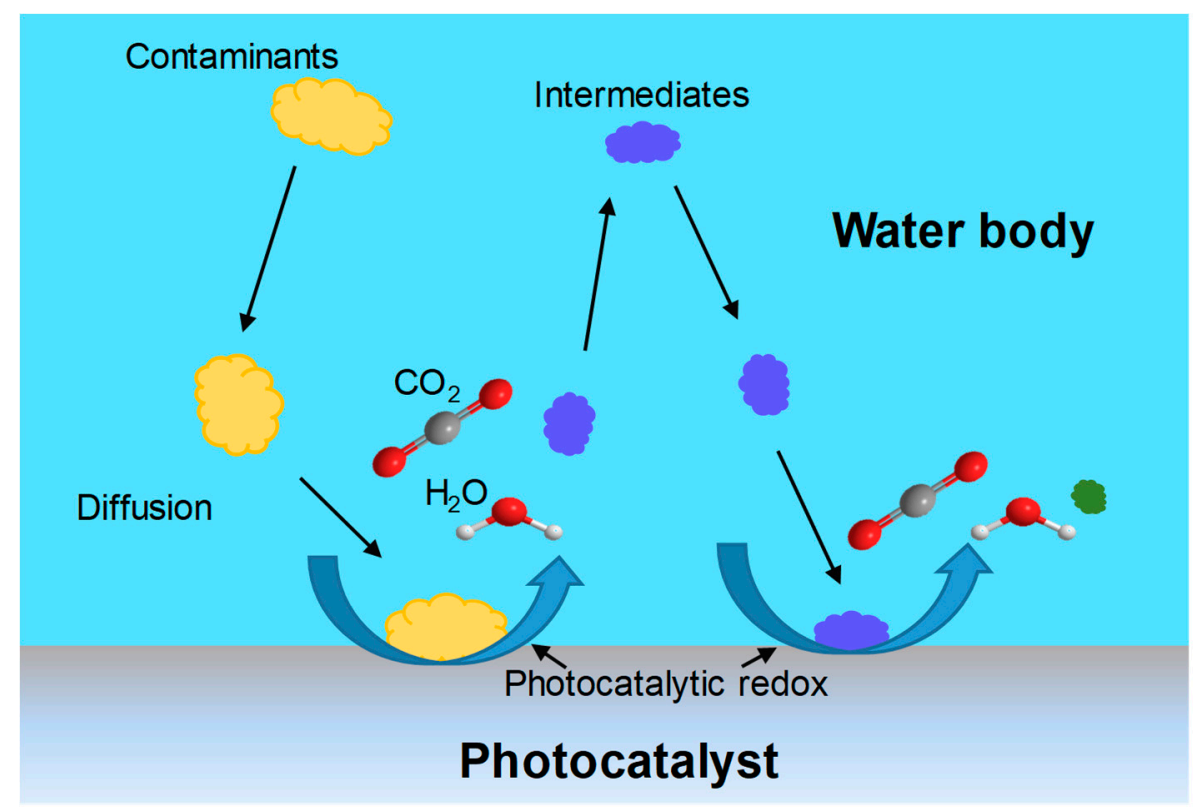

Figure 2. Schematic diagram demonstrating the removal of contaminants in water with the presence of photocatalysts $[18,29,30]$. 


\section{Heteroatoms Doping}

Recently, the strategy of introducing heteroatoms into the lattice of corresponding semiconductors has been widely employed to regulate the band gap of the semiconductor photocatalysts so as to improve their absorption capacity for visible lights, which takes up almost $45 \%$ in the solar light spectrum [31]. In general, the most commonly used dopants in semiconductors (e.g., $\mathrm{TiO}_{2}$ ) could be classified as the metal cations and the non-metallic elements [32,33].

\subsection{Metal Cations Doping}

The most-used metal cation dopants for semiconductors mainly involve transition metal ions, such as $\mathrm{Fe}^{3+}, \mathrm{Co}^{3+}, \mathrm{Mo}^{5+}, \mathrm{Ru}^{3+}, \mathrm{Ag}^{+}, \mathrm{Cu}^{2+}, \mathrm{Rb}^{+}, \mathrm{Cr}^{3+}, \mathrm{V}^{4+}$, etc. [32,34-37]. In most cases, the redox energy states of those employed metal cations lie within the band gap states of corresponding semiconductors (e.g., $\mathrm{TiO}_{2}$ ); therefore, the introduction of those metal ions will result in an intraband state near the $\mathrm{CB}$ or VB edge of a semiconductor. Consequently, the red shift in band gap absorption of a metal-cation-doped semiconductor is mainly contributed by the charge migration between the $\mathrm{d}$ electrons of the doped cations and the $\mathrm{CB}$ (or VB) of the corresponding semiconductors. In addition, the doped metal cations could act as an electron-hole trap, regulating the charge carrier equilibrium concentration [38-40]. Although some transition metal cations could provide new energy levels as electron donors or acceptors, and virtually improved the visible light absorption capacity of corresponding semiconductors, this approach is also known to suffer from many disadvantages, such as bad thermal stability, significant increase in the carrier-recombination centers, and the high cost for an expensive facility, which are critical limitations for the generalization of this strategy.

\subsection{Non-Metallic Anions Doping}

Alternatively, doping the semiconductors with appropriate non-metallic anions has been proven to be a facile way to regulate the intrinsic electronic structure of semiconductors and could construct various heteroatomic surface structures such that the resultant non-metallic-anion-doped semiconductors exhibit improved photocatalytic performances under solar light irradiation [33,41]. In general, the chemical states and locations are key factors for the regulation of the electronic state of the dopant and the corresponding heteroatomic surface structures of the composite semiconductor catalysts. According to a previous study [18], three requirements needed to be satisfied for the doping of a semiconductor: (i) the doping process should construct states in the band gap of corresponding semiconductors with an enhanced visible light absorption capacity, (ii) the CB minimum including the doped states should be equal to that of the semiconductor's or higher than that of the $\mathrm{H}_{2} / \mathrm{H}_{2} \mathrm{O}$ level such that the photoreduction can be conducted, and (iii) the states in the gap should sufficiently overlap with the band states of semiconductors to ensure that the photoexcited carriers could migrate to the surface of catalysts within their lifetime. Based on the abovementioned principles, various elements, including C, N, F, P, and S, were employed to substitute for the $\mathrm{O}$ in $\mathrm{TiO}_{2}$ [42], and the results showed that $\mathrm{N}$ was the most effective dopant for the improvement of visible-light photocatalysis of $\mathrm{TiO}_{2}$ because the $p$ states of $\mathrm{N}$ can narrow the band gap of $\mathrm{N}$-doped $\mathrm{TiO}_{2}$ via mixing with the $\mathrm{O} 2 p$ states [43]. Moreover, owing to the comparable atomic size with oxygen, small ionization energy, and high stability, the nitrogen has been one of the most promising elements for promoting the photocatalysis performance of the semiconductors. In general, the doped $\mathrm{N}$ in the $\mathrm{TiO}_{2}$ could be classified as the substitutional type and interstitial type (Figure 3), the substitutional type N-doped $\mathrm{TiO}_{2}$ is attributed to the oxygen replacement, while the interstitial type is attributed to the additional $\mathrm{N}$ element in the lattice of $\mathrm{TiO}_{2}$ [41]. Up to now, the $\mathrm{N}$-doping of semiconductors can be realized via several strategies, and the most-used techniques with certain industrial application prospects could be mentioned as the magnetron sputtering, ion implantation, chemical vapor deposition, atomic layer deposition, and sol-gel and combustion method, which will be discussed as follows. 

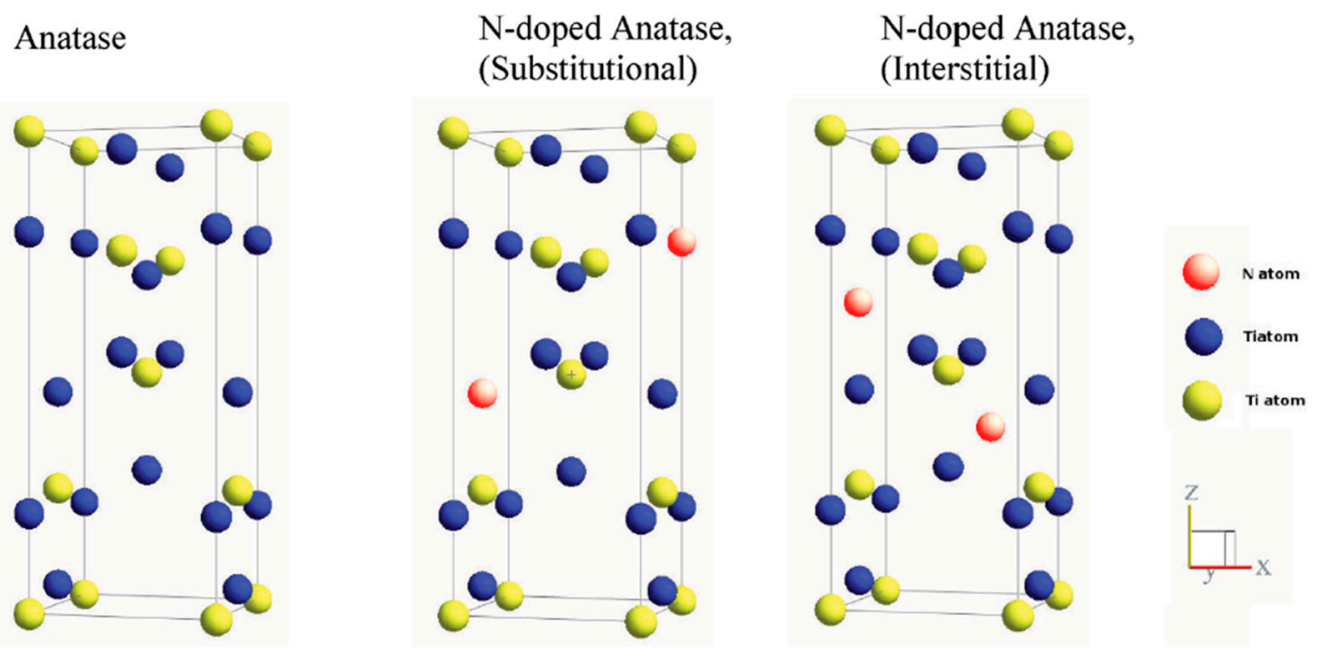

Figure 3. Schematic diagram demonstrating the $\mathrm{N}$ doping in the lattice of $\mathrm{TiO}_{2}$. Adapted with permission from Reference [41]. Copyright (2011) Royal Society of Chemistry.

\subsubsection{Magnetron Sputtering Method}

The magnetron sputtering method is widely used for the preparation of various hybrid semiconductors. For example, Kitano et al. [44] fabricated nitrogen-substituted $\mathrm{TiO}_{2}$ thin films by using a radio frequency magnetron sputtering (RF-MS) method. The $\mathrm{N}_{2} / \mathrm{Ar}$ gas mixtures with different concentration of $\mathrm{N}_{2}$ was used as the sputtering gas. They systematically investigated the influence of nitrogen content on the properties of the obtained $\mathrm{N}-\mathrm{TiO}_{2}$ thin films via regulating the concentration of $\mathrm{N}_{2}$ in the sputtering gases. Meanwhile, they proved that the extent of substitution of oxygen positions with $\mathrm{N}$ in the lattice of $\mathrm{TiO}_{2}$ as well as the surface morphologies of $\mathrm{TiO}_{2}$ could be controlled well. As a result, the visible light absorption capacity of the obtained $\mathrm{N}-\mathrm{TiO}_{2}$ was obviously enhanced with bands up to $550 \mathrm{~nm}$, and it was found that the band red shift extent was closely related to the content of the substituted $\mathrm{N}$ element in the $\mathrm{TiO}_{2}$ lattice. Moreover, they found that the as-prepared $\mathrm{N}-\mathrm{TiO}_{2}$ photocatalyst exhibited an optimized photocatalysis reactivity with the $\mathrm{N}$ content of $6 \%$. This result was because of the excessive substituted $\mathrm{N}$, which causes the formation of undesirable $\mathrm{Ti}^{3+}$ species and acts as the recombination centers to decrease the photocatalytic activity [44]. Apart from the $\mathrm{TiO}_{2}$, some other N-doped semiconductors could also be prepared based on the RF-MS method. Recently, Salah et al. [45] fabricated a series of $\mathrm{N}$-doped $\mathrm{ZnO}$ nanoparticles films by employing the RF-MS method. As shown in Figure 4, the obtained N-doped $\mathrm{ZnO}$ films exhibited an improved response to the visible light, and possessed significantly enhanced degradation/mineralization performance for 2-chlorophenol (2-CP), 4-chlorophenol (4-CP), and 2,4-dichlorophenoxyaceticacid (2,4-D) solely under the drive of natural sunlight. 

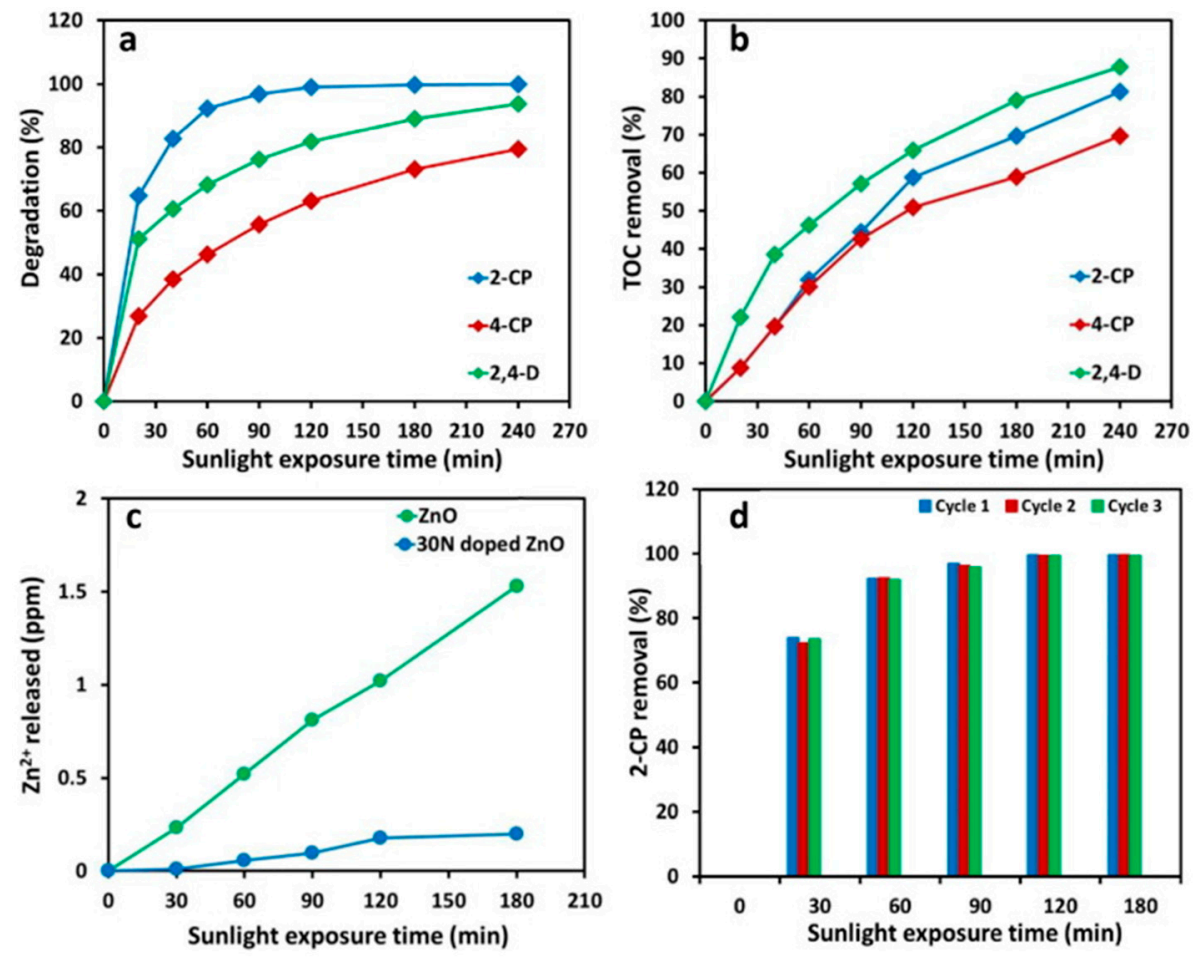

Figure 4. (a) The degradation and (b) mineralization of N-doped $\mathrm{ZnO}$ films for 2-CP, 4-CP, and 2,4-D. (c) The stability of pristine $\mathrm{ZnO}$ and $\mathrm{N}$-doped $\mathrm{ZnO}$ film. (d) The stability and reusability of an $\mathrm{N}$-doped $\mathrm{ZnO}$ film for the degradation of 2-CP. Adapted with permission from Reference [45]. Copyright (2016) Elsevier.

\subsubsection{Ion Implantation Method}

The ion implantation method as a typical materials engineering strategy that can effectively regulate the physical, chemical, and electronic properties of semiconductors, and the operation process does not involve any other elements except the selected element, which ensures the purity of the dopant [46]. Moreover, owing to the controllable parameters of ion beam implantation, such as ion element, ion energy, ion density, uniformity of ion beam, and the doping efficiency, ion beam implantation is a powerful approach for the heteroatom doping of semiconductors. For example, Tang et al. [47] fabricated an $\mathrm{N}$-doped $\mathrm{TiO}_{2}$ layer with macrospores on a titanium substrate by using the plasma-based ion implantation method. The fabrication process involves four steps: (i) a helium plasma was employed to generate He bubbles in the substrate, (ii) an oxygen plasma treatment and a followed annealing in air were used to obtain rutile and anatase phases of $\mathrm{TiO}_{2}$, (iii) an Ar ion sputtering method was used to exposure the He bubbles on the surface; and (iv) the pre-treated samples were doped by nitrogen though the nitrogen beam ion implantation method. Moreover, co-doping of two or more non-metallic anions into a semiconductor photocatalyst (e.g., $\mathrm{TiO}_{2}$ ) could also be realized using the ion implantation method. For example, Song et al. [48] prepared C/N-implanted single-crystalline rutile $\mathrm{TiO}_{2}$ nanowire arrays by using carbon and nitrogen ions beam to treat the as-prepared $\mathrm{TiO}_{2}$ nanowire arrays. After an annealing treatment, the obtained $\mathrm{C} / \mathrm{N}$-doped $\mathrm{TiO}_{2}$ nanowire arrays exhibited a superior visible light response activity, which was attributed to the synergistic effect between the doped $\mathrm{C}$ and $\mathrm{N}$ atoms. Their work proved that the co-doped $\mathrm{C}$ and $\mathrm{N}$ in the lattice of $\mathrm{TiO}_{2}$ not only greatly improves the visible light absorption capability, but also enhances the separating and transferring property of photo-generated electron-hole pairs (Figure 5). 

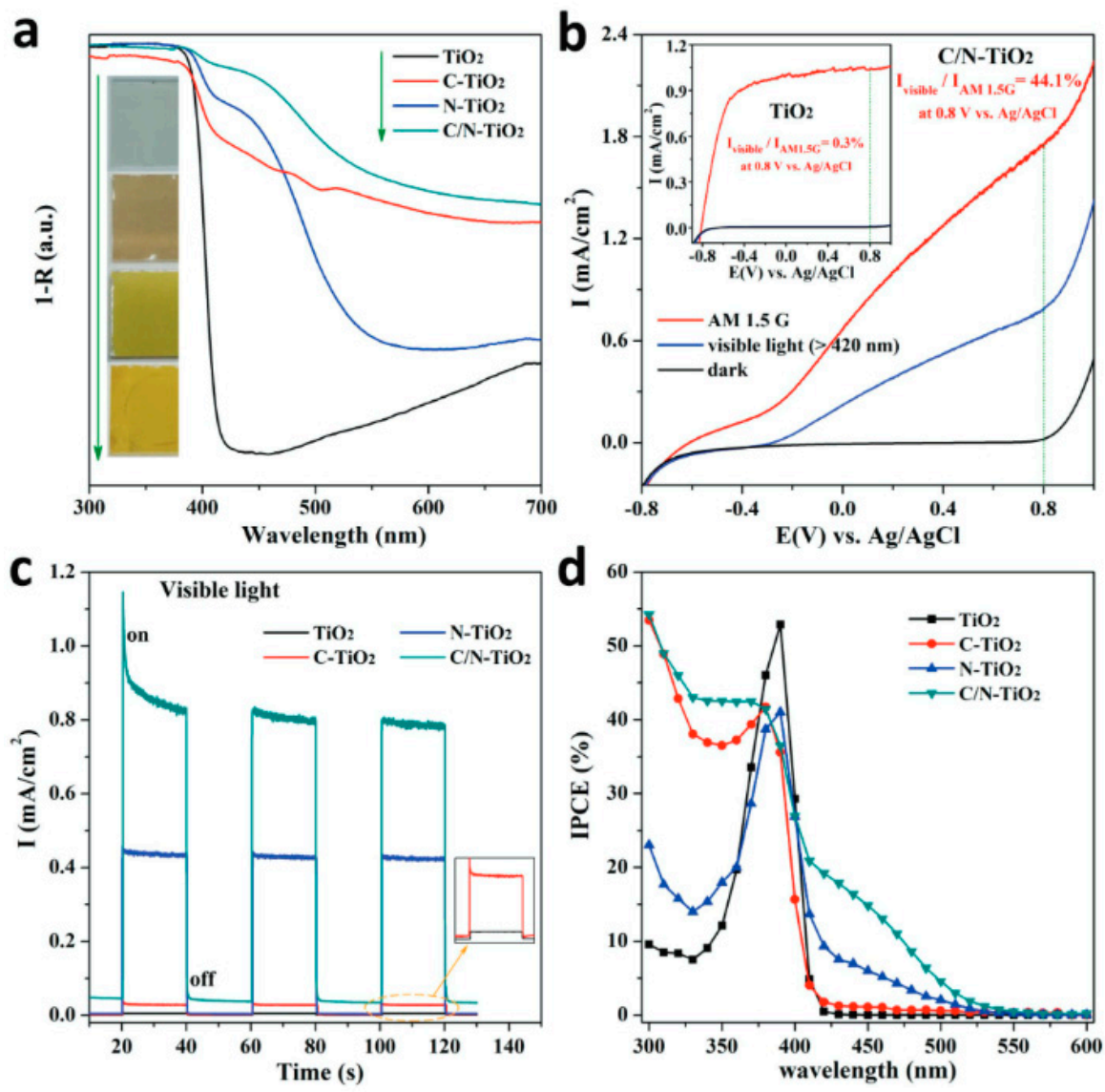

Figure 5. (a) UV-vis absorption spectra of $\mathrm{TiO}_{2}$ and various doped $\mathrm{TiO}_{2}$. (b) Linear sweep voltammograms of $\mathrm{C} / \mathrm{N}-\mathrm{TiO}_{2}$ and $\mathrm{TiO}_{2}$. (c) Photo-response of $\mathrm{TiO}_{2}$ and the various doped $\mathrm{TiO}_{2}$ samples under visible light. (d) Incident photon-to-current conversion efficiency spectra of $\mathrm{TiO}_{2}$ and various doped $\mathrm{TiO}_{2}$. Adapted with permission from Reference [48]. Copyright (2018) Wiley.

\subsubsection{Chemical Vapor Deposition Method}

Chemical vapor deposition (CVD) is a low-cost and scalable technique, which can directly grow a solid-phase material from a gas phase containing specific precursors. The CVD method has been widely used for the fabrication of semiconductors and the corresponding composite of oxides, sulfides, nitrides, and other mixed anion materials [49]. For example, Lee et al. [50] prepared $\mathrm{TiO}_{2}$ composite materials doped by $\mathrm{C}$ (TiOC) and $\mathrm{N}$ (TiON) with the titanium tetraisopropoxide (TTIP), oxygen, and $\mathrm{NH}_{3}$ as the precursors via combing the CVD method with a fluidized bed. The results demonstrated that the visible light photocatalysis performance of the composite $\mathrm{TiO}_{2}$ (e.g., $\mathrm{TiON}$ ) was significantly improved compared to the commercial $\mathrm{TiO}_{2}$ catalyst (P25, Degussa). Similarly, Kafizas et al. [51] employed a combinatorial atmospheric pressure chemical vapor deposition (cAPCVD) method to prepare an anatase $\mathrm{TiO}_{2}$ film with a gradating $\mathrm{N}$ content. The obtained $\mathrm{TiO}_{2}$ film exhibited a gradating substitutional $\left(\mathrm{N}_{\mathrm{s}}\right)$ and interstitial $\left(\mathrm{N}_{\mathrm{i}}\right)$ nitrogen concentration, and the transition process from predominantly $\mathrm{N}_{\mathrm{s}}$-doped $\mathrm{TiO}_{2}$ to $\mathrm{N}_{\mathrm{s}} / \mathrm{N}_{\mathrm{i}}$ mixtures, and finally to purely $\mathrm{N}_{\mathrm{i}}$-doped $\mathrm{TiO}_{2}$ was precisely characterized. In addition, the UV and visible light photocatalytic activities of the obtained $\mathrm{N}$-doped $\mathrm{TiO}_{2}$ were evaluated. As a result, this work demonstrated that $\mathrm{N}_{\mathrm{i}}$-doped anatase $\mathrm{TiO}_{2}$ results in a better visible light photocatalytic activity than that of predominantly $\mathrm{N}_{\mathrm{s}}$-doping. They proved that the different influences of substitutional and interstitial nitrogen doping on the photocatalytic activity of $\mathrm{TiO}_{2}$ were due to that the greater stability of electron-holes in $\mathrm{N}_{\mathrm{i}}$-doped $\mathrm{TiO}_{2}$ compare with that of $\mathrm{N}_{\mathrm{s}}$-doped $\mathrm{TiO}_{2}$, while the propensity of the $\mathrm{N}_{\mathrm{s}}$-doped $\mathrm{TiO}_{2}$ for recombination is greater. This result indicated that the doped structures is well-deigned to improve the photocatalytic activity of a semiconductor. Additionally, the CVD could also be combined with other materials 
synthesis strategy; for example, as shown in Figure 6, Youssef et al. [52] prepared the N-doped anatase films via a one-step low-frequency plasma enhanced chemical vapor deposition (PECVD) process. Furthermore, they demonstrated that this method did not need the subsequential annealing step or post-incorporation of the doping agent, and the as-prepared $\mathrm{N}-\mathrm{TiO}_{2}$ film exhibited good visible-light-induced photocatalytic performance.

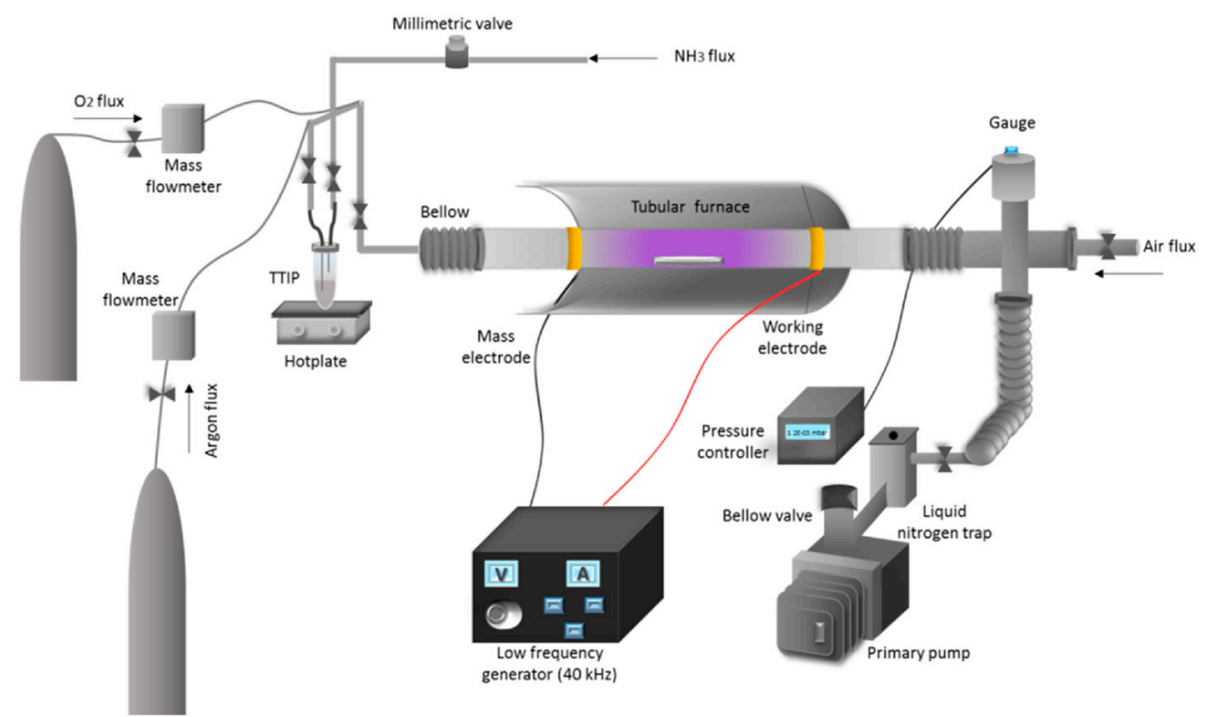

Figure 6. Schematic view of the capacitively-coupled low frequency PECVD reactor. Adapted with permission from Reference [52]. Copyright (2017) Elsevier.

\subsubsection{Atomic Layer Deposition}

The atomic layer deposition (ALD) method is a recently developed and facile strategy for the element doping of semiconductors. Actually, ALD is a gas-phase deposition process based on alternate surface reactions of the substrates, and the ALD method possesses several advantages, such as good reproducibility, considerable conformality, and excellent uniformity [53]. Consequently, the ALD method is considered as a promising strategy for the preparation of doped and composite photocatalysts [54]. For example, Pore et al. [55] prepared a series of $\mathrm{N}-\mathrm{TiO}_{2}$ films via employing the ALD processes. In this study, $\mathrm{TiCl}_{4}$ was used as the titanium precursor and there were two ALD cycles during the fabrication process: (i) a thin layer of TiN was grown from the $\mathrm{TiCl}_{4}$ and $\mathrm{NH}_{3}$; and (ii) $\mathrm{TiO}_{2}$ was deposited on the surface of $\mathrm{TiN}$ layer from $\mathrm{TiCl}_{4}$ and $\mathrm{H}_{2} \mathrm{O}$, meanwhile the as-prepared TiN layer was part-oxidized to $\mathrm{TiO}_{2}$, thus resulting in the $\mathrm{TiO}_{2-x} \mathrm{~N}_{\mathrm{x}}$. Moreover, the nitrogen concentration of the obtained $\mathrm{TiO}_{2-x} \mathrm{~N}_{\mathrm{x}}$ could be well controlled via changing the ratio of $\mathrm{TiN}$ and $\mathrm{TiO}_{2}$ deposition cycles. Similarly, Lee et al. [56] reported a facile and effective vapor-phase synthesis strategy to prepare a conformal $\mathrm{N}-\mathrm{TiO}_{2}$ thin film based on the ALD process. As shown in Figure 7, the fabrication process of the corresponding $\mathrm{N}-\mathrm{TiO}_{2}$ film involved four main steps: (i) pulse the $\mathrm{TiCl}_{4}$ vapor on the surfaces of a substrate to produce a monolayer of chemisorbed $\mathrm{TiCl}_{\mathrm{X}}$ species; (ii) remove the remaining unreacted $\mathrm{TiCl}_{4}$ and corresponding $\mathrm{HCl}$ byproducts using nitrogen gas; (iii) $\mathrm{NH}_{4} \mathrm{OH}$ as the nitrogen source was subsequently pulsed to generate a mixture of gaseous $\mathrm{H}_{2} \mathrm{O}$ and $\mathrm{NH}_{3}$, which react with the as-prepared $\mathrm{TiCl}_{\mathrm{X}}$ species to obtain the $\mathrm{N}-\mathrm{TiO}_{2}$; and (iv) remove the unreacted precursors and $\mathrm{HCl}$ byproducts again. This cycle could be repeated to achieve the $\mathrm{N}^{-\mathrm{TiO}_{2}}$ film with the desired thickness. The as-prepared $\mathrm{N}-\mathrm{TiO}_{2}$ exhibited significantly enhanced photocatalytic degradation performance for organic pollutants solely driven by the solar irradiation. 


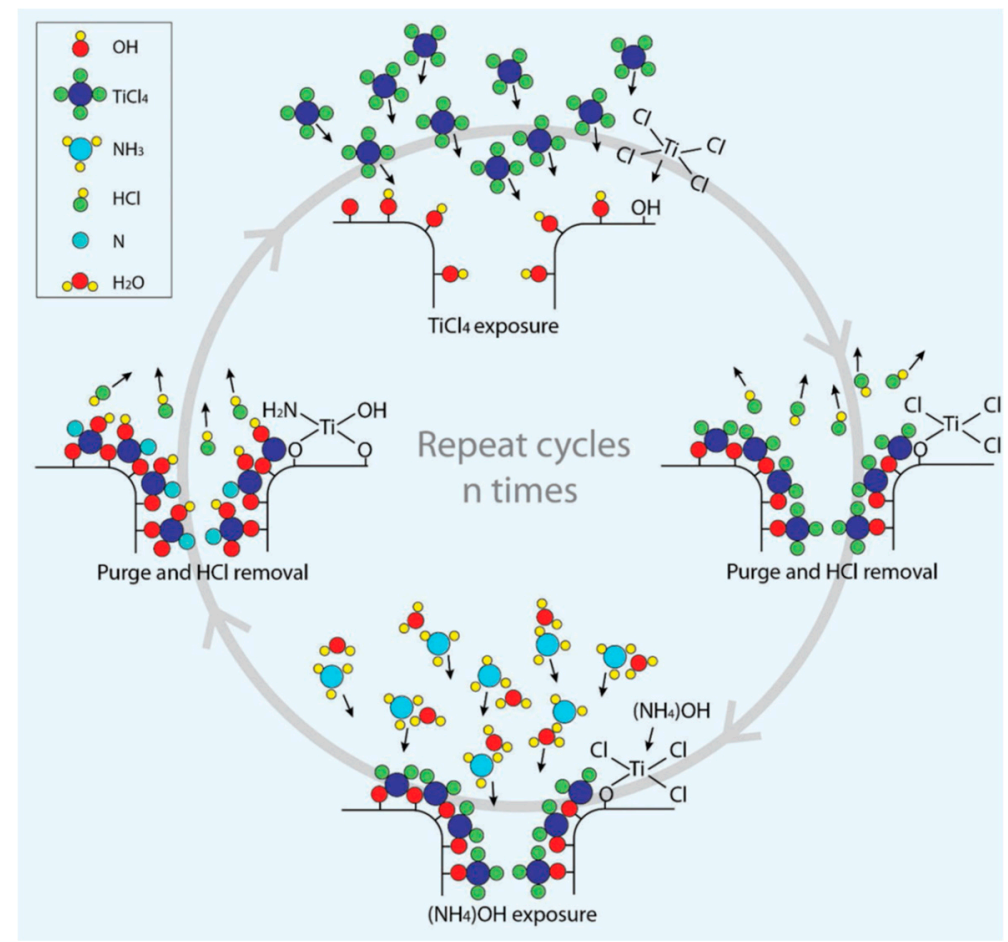

Figure 7. Schematic illustration demonstrating the synthesis process of the $\mathrm{N}$-doped $\mathrm{TiO}_{2}$ conformal film via the ALD method. Adapted with permission from Reference [56]. Copyright (2017) Wiley.

\subsubsection{Sol-Gel and Combustion Method}

Compared with the abovementioned synthesis approaches, the sol-gel and combustion method is a facile and low-cost strategy for the preparation of various semiconductors and the corresponding hybrid semiconductors. With the merits of simplicity and the possibility of controlling the synthesis conditions, the sol-gel methods have been well developed and several extended sol-gel techniques have been invented to fabricate new types of semiconductor photocatalysts. For example, Albrbar et al. [57] reported the synthesis of a series of mesoporous anatase $\mathrm{TiO}_{2}$ powders doped by $\mathrm{N}$, and $\mathrm{S}$, as well as the N,S co-doped anatase $\mathrm{TiO}_{2}$ powder using a non-hydrolytic sol-gel process. During the gel synthesis process, titaniumtetrachloride and titaniumisopropoxide were used as the precursor of $\mathrm{Ti}$, dimethylsulfoxide (DMSO) was used as the precursor of $\mathrm{S}$, and $\mathrm{NH}_{3}$ was used as the precursor of $\mathrm{N}$. For the preparation of S-doped $\mathrm{TiO}_{2}$, the obtained gel derived from the solvent of DMSO was calcined in air, while $\mathrm{N}$ and $\mathrm{S}$ co-doped $\mathrm{TiO}_{2}$ was obtained when the gel was annealed in the atmosphere of $\mathrm{NH}_{3}$. In addition, the pristine $\mathrm{TiO}_{2}$ and corresponding $\mathrm{N}$-doped $\mathrm{TiO}_{2}$ was further obtained via calcining the gel derived from the solvent of cyclohexane in air and $\mathrm{NH}_{3}$, respectively. In their studies, the photocatalytic activities of the samples were evaluated via the degradation of dye C.I. Reactive Orange16 in water under the irradiation of visible light. The obtained results showed that the $\mathrm{N}$-doped $\mathrm{TiO}_{2}$ exhibited better visible-light photocatalytic activity compared with the pristine $\mathrm{TiO}_{2}$ and S-doped $\mathrm{TiO}_{2}$. Similarly, the sol-gel method is also versatile enough to be combined with other materials synthesis techniques. Most recently, Rajoriya et al. [58] successfully fabricated a samarium $(\mathrm{Sm})$ and nitrogen $(\mathrm{N})$ co-doped $\mathrm{TiO}_{2}$ photocatalyst through an ultrasound-assisted sol-gel process (Figure 8), where they found that after doping $\mathrm{TiO}_{2}$ with $\mathrm{Sm}$ and $\mathrm{N}$, the photocatalytic degradation performance of the $\mathrm{TiO}_{2}$ for 4-acetamidophenol was greatly improved owing to the significantly improved separation efficiency of the photo-generated electron-hole pair. 


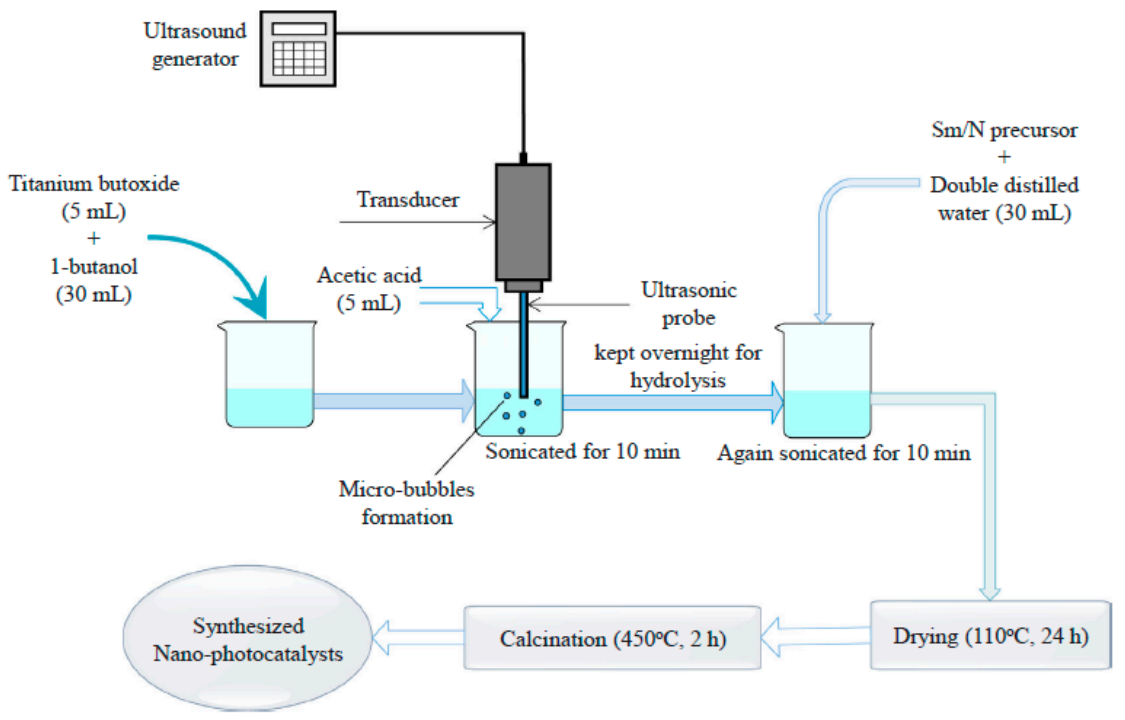

Figure 8. Schematic illustrating the ultrasound assisted sol-gel synthesis process of the Sm/N doped $\mathrm{TiO}_{2}$. Adapted with permission from Reference [58]. Copyright (2019) Elsevier.

\section{Heterojunctions Construction}

Besides the abovementioned heteroatoms doping strategy, constructing heterojunctions in photocatalysts is also considered as one of the most promising approaches for improving the photocatalysis performance of semiconductors due to its feasibility and effectiveness for the spatial separation of electron-hole pairs. More specifically, the heterojunction is defined as the formed interface between two semiconductors with the unequal band structure, which can form band alignments $[59,60]$. In fact, there have been several types of heterojunction structures, which could be considered as the conventional heterojunction structures, and the new generation of heterojunction structures.

\subsection{Conventional Heterojunctions}

In general, the conventional heterojunctions can be classified as three types depending on the different band gaps of the composite semiconductors, which are type I with a straddling gap, type II with a staggered gap, and type III with a broken gap (Figure 9) [59]. As for the type I heterojunction, the $\mathrm{VB}$ and $\mathrm{CB}$ of semiconductor $\mathrm{A}$ are lower and higher than the corresponding $\mathrm{VB}$ and $\mathrm{CB}$ of semiconductor $B$, respectively. As a result, the photo-generated electrons and holes transfer to the $C B$ and VB of semiconductor $\mathrm{B}$, which is negative for the separation of electron-hole pairs. Moreover, the redox reaction of the composite semiconductors with a type I heterojunction will conduct on the surface of semiconductor B with a lower redox potential, therefore the redox ability of the whole photocatalyst may be suppressed. Meanwhile, in the composite semiconductor system with type II heterojunctions, the $\mathrm{VB}$ and $\mathrm{CB}$ of semiconductor $\mathrm{A}$ are higher than that of semiconductor $\mathrm{B}$, thus the photo-generated electrons will migrate from the $\mathrm{CB}$ of semiconductor $\mathrm{A}$ to that of semiconductor $\mathrm{B}$ with a lower reduction potential, and the corresponding holes in the VB of semiconductor $\mathrm{B}$ will migrate to semiconductor A with a lower oxidation potential, thus a spatial separation of electron-hole pairs will be completed. However, the band gap of the two semiconductors will not overlap in the type III heterojunctions, and as a result, there is no transmission or separation of electrons and holes between semiconductor A and semiconductor B. Consequently, the type II heterojunction is the most effective structure for improving the photocatalysis performance of semiconductors, and has received a great deal of research attention. 


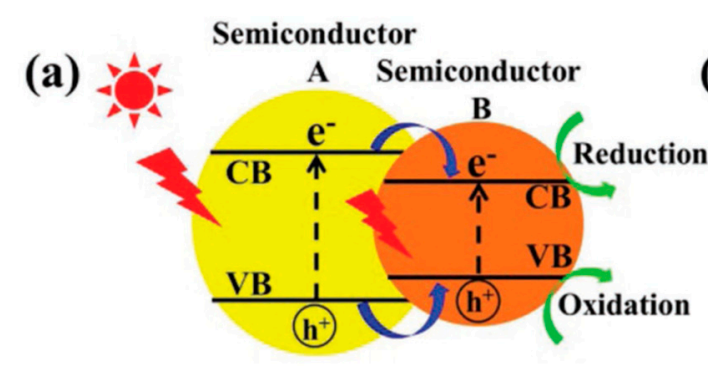

Straddling gap (type-I)

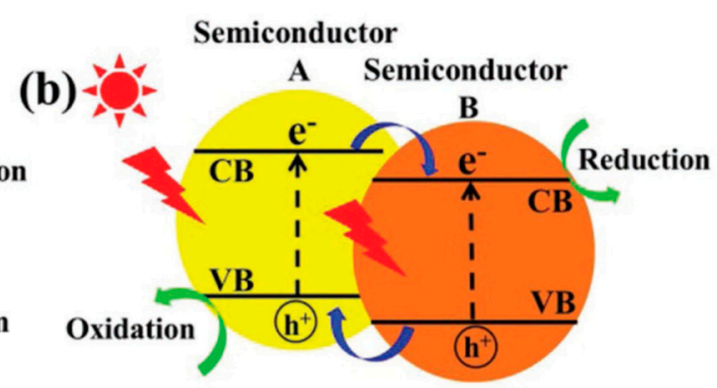

Staggered gap (type-II)

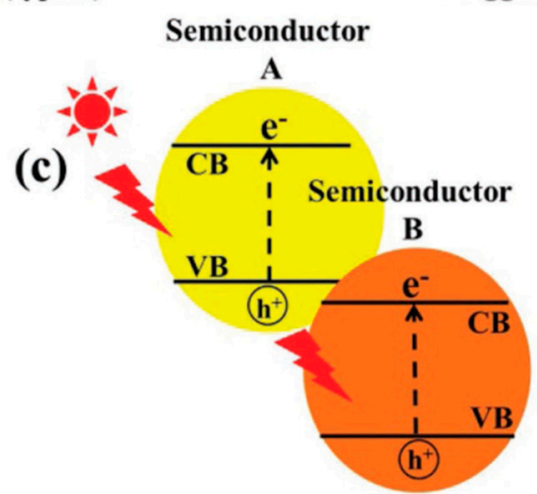

Broken gap (type-III)

Figure 9. Schematic illustrating the photocatalysis mechanism of the three different types of heterojunction photocatalysts: (a) type-I, (b) type-II, and (c) type-III. Adapted with permission from Reference [59]. Copyright (2017) Wiley.

Up to now, several type-II heterojunction photocatalysts have been developed by creating two different phases in the same semiconductor, or directly compositing different semiconductors together [60,61]. For example, Yu et al. [62] once created the anatase-brookite dual-phase in a $\mathrm{TiO}_{2}$ photocatalyst to form a type-II heterojunction via hydrolyzing the titanium tetraisopropoxide in water and an ethanol- $\mathrm{H}_{2} \mathrm{O}$ mixture solution. They found that the co-presence of brookite and anatase phases in the $\mathrm{TiO}_{2}$ significantly enhanced the photocatalysis performance. After that, Uddin et al. [63] successfully fabricated the mesoporous $\mathrm{SnO}_{2}-\mathrm{ZnO}$ heterojunction photocatalysts using a two-step synthesis strategy. Furthermore, they had carefully examined the band alignment, the results showed that the obtained $\mathrm{SnO}_{2}-\mathrm{ZnO}$ heterojunction photocatalyst possessed a type-II band alignment and exhibited higher photocatalytic activity for the degradation of methyl blue in water than that of the individual $\mathrm{SnO}_{2}$ and $\mathrm{ZnO}$ nanocatalysts (Figure 10). Apart from the inorganic semiconductors, organic semiconductors could also be incorporated with the semiconductors to form the type-II heterojunction. For example, Shirmardi et al. [64] used polyaniline (PANI) as the organic semiconductor combined with ZnSe nanoparticles via a simple and cost-effective co-precipitation method in the ambient conditions. The obtained ZnSe/PANI nanocomposites exhibited obvious enhancement in the photocatalytic performance compared to that of the pristine ZnSe nanoparticles. 
(a)

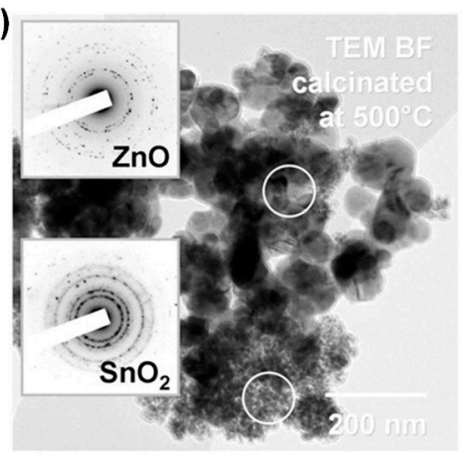

(b)

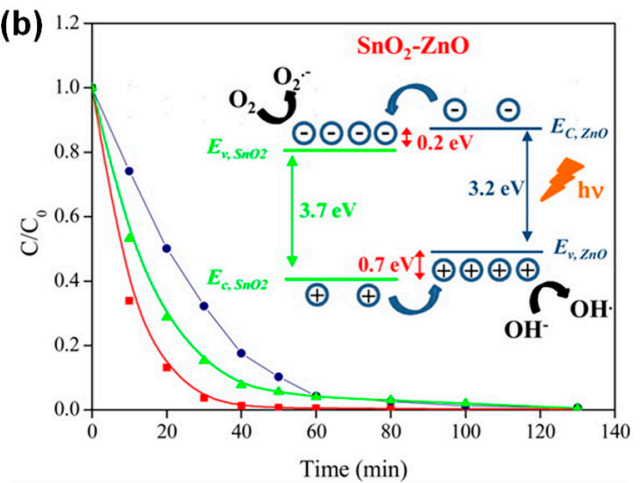

Figure 10. (a) Nanostructures of $\mathrm{SnO}_{2}-\mathrm{ZnO}$ composite photocatalysts. (b) The corresponding photocatalytic performances of $\mathrm{SnO}_{2}-\mathrm{ZnO}$ (red line with square dots), $\mathrm{SnO}_{2}$ (green line with triangle dots), and $\mathrm{ZnO}$ (blue line with circle dots). Adapted with permission from Reference [63].

Copyright (2012) American Chemical Society.

\subsection{New Generation of Heterojunctions}

Although the conventional type-II heterojunctions are capable of spatially separating the photo-generated electron-hole pairs, there remain several critical limitations, such as the relatively weak redox ability due to the lower reduction and oxidation potentials, and the suppressed migration of electrons and holes due to the electrostatic repulsion [59]. Recently, in order to overcome the abovementioned limitations, a new generation of heterojunctions have been developed, including the $\mathrm{p}$-n heterojunctions, the surface heterojunctions, the Z-scheme heterojunctions, and the semiconductor/carbon heterojunctions. Here we will give a brief introduction of each kind of these newly developed heterojunctions.

\subsection{1. $\mathrm{p}-\mathrm{n}$ Heterojunctions}

The p-n heterojunctions could be obtained by incorporating a p-type semiconductor with an $n$-type semiconductor, and it has been proved that the formation of $p$ - $n$ heterojunctions are effective for improving the photocatalytic performance of composite catalysts $[65,66]$. In general, before the irradiation of light, there is an internal electric field in the region closed to the p-n interface due to the electron-hole diffusion tendency of the composite semiconductors system with unequal Fermi levels $[59,67]$. Alternatively, when the composite semiconductors are irradiated by a light, and the energy state of the photon is beyond the band gaps of both p-type and n-type semiconductors, electron-hole pairs will be generated in the corresponding semiconductors. However, due to the presence of an internal electric field, the photo-generated electrons and holes will transfer to the $\mathrm{CB}$ of the n-type semiconductor and the VB of p-type semiconductor, respectively. Furthermore, it has been proved that this spatial separation of the photo-generated electron-hole pairs is much more efficient compared with that of conventional type-II heterojunction because of the synergy of the internal electric field and band alignment $[59,68]$. As a result, a variety of composite semiconductors with the $p-n$ heterojunctions have been created for the application of photocatalysis. For example, Wen et al. [69] reported the fabrication of a $\mathrm{BiOI} / \mathrm{CeO}_{2} \mathrm{p}$-n junction using a facile in situ chemical bath method. The result demonstrated that the $\mathrm{BiOI} / \mathrm{CeO}_{2}$ composite with a mole ratio of $1: 1$ exhibited a superior photocatalytic performance for the decomposition of bisphenol A (BPA) and methylene orange under visible light irradiation. Most recently, as shown in Figure 11, our group reported a facile method for the preparation of $\mathrm{SnS}_{2} / \mathrm{MoO}_{3}$ hollow nanotubes based on the hydrothermal method [70]. The obtained $\mathrm{SnS}_{2} / \mathrm{MoO}_{3}$ hollow nanotubes exhibit a typical p-n heterojunction structure, and a synergistic effect between $\mathrm{MoO}_{3}$ and $\mathrm{SnS}_{2}$ was proven to yield an optimal hydrogen peroxide production performance. 


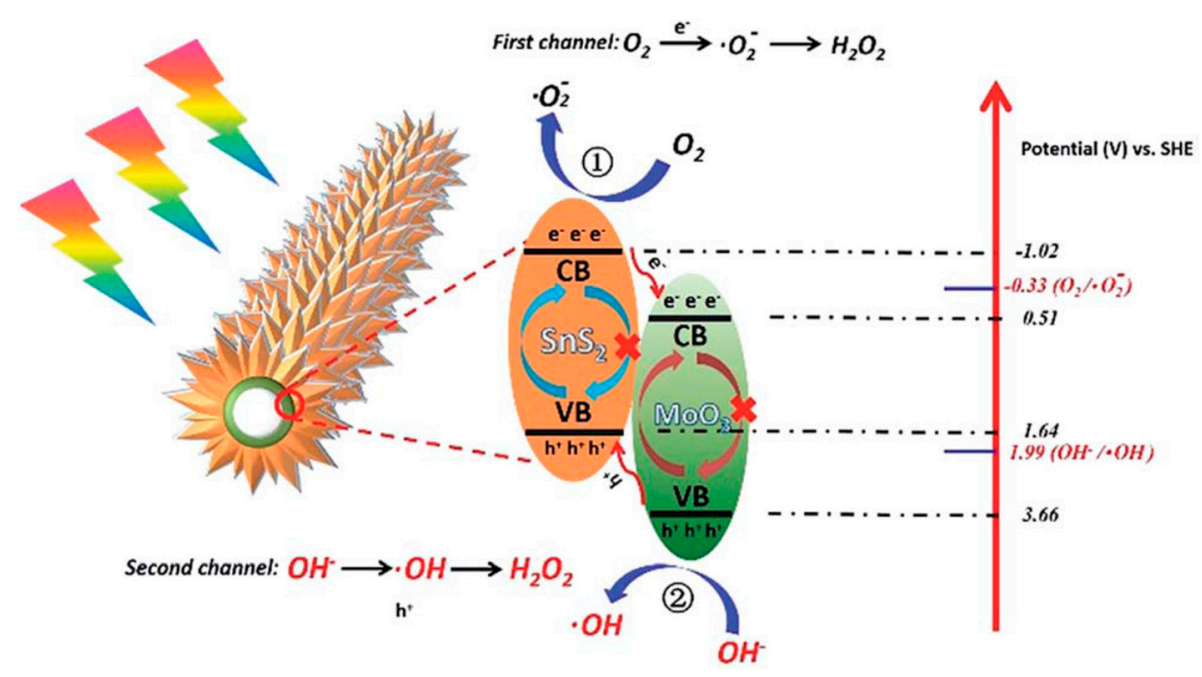

Figure 11. Schematic illustration of the $\mathrm{SnS}_{2} / \mathrm{MoO}_{3}$ hollow nanotubes and its photocatalysis mechanism with a two-channel pathway. Adapted with permission from Reference [70]. Copyright (2018) Royal Society of Chemistry.

\subsubsection{Surface Heterojunctions}

As reported before, a surface heterojunction can be created between two crystal facets of a single semiconductor [59,71]. For example, Yu et al. [72] proved that the formation of a heterojunction between the (001) and (101) facets in $\mathrm{TiO}_{2}$ contribute significantly toward the enhancement of photocatalytic activity. This method enables the construction of a heterojunction on the surface of a single semiconductor, which is less costly because only one semiconductor is used. They also demonstrate that there is an optimal ratio for the (001) and (101) facets in the anatase $\mathrm{TiO}_{2}$ for the improvement of its photocatalysis performance. Subsequently, Gao et al. [73] found that the surface heterojunction of $\mathrm{TiO}_{2}$ could be self-adjusted, and its photocatalytic activity could be significantly improved via combining a proper surface heterojunction with the Schottky junction. Apart from the $\mathrm{TiO}_{2}$, Bi-based semiconductors could also be employed for the design of photocatalysts with surface heterojunctions. Most recently, as shown in Figure 12, Lu et al. [74] synthesized a tetragonal BiOI photocatalyst by regulating the amount of water in the hydrolysis process at room temperature. The as-prepared photocatalyst possessed a typical surface heterojunction structure between (001) facets and (110) facets, and exhibited a promoted photocatalytic performance for the degradation of organic contaminants in water under visible light. 
(a)
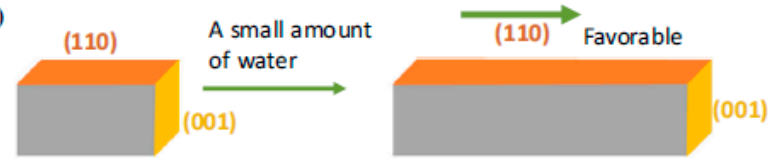

(b)
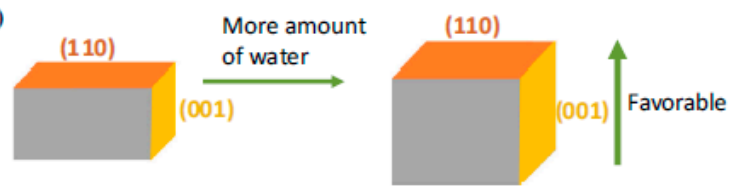

(c)

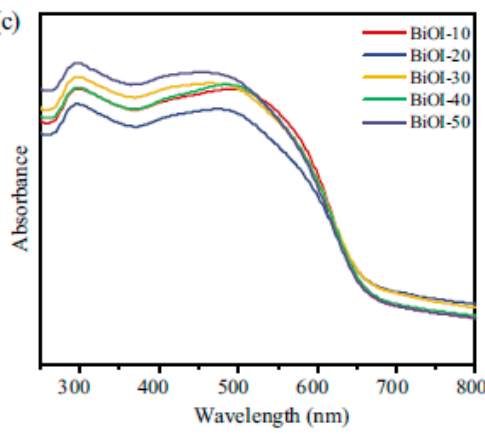

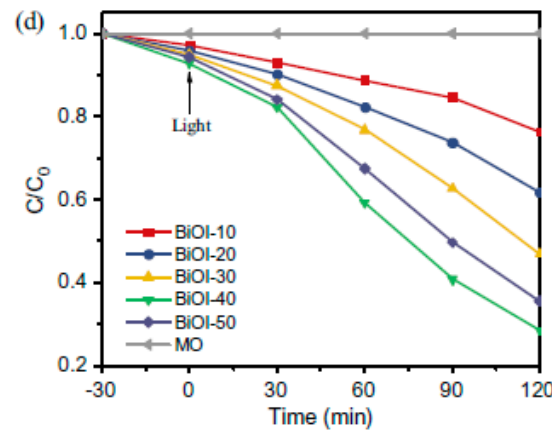

(e)

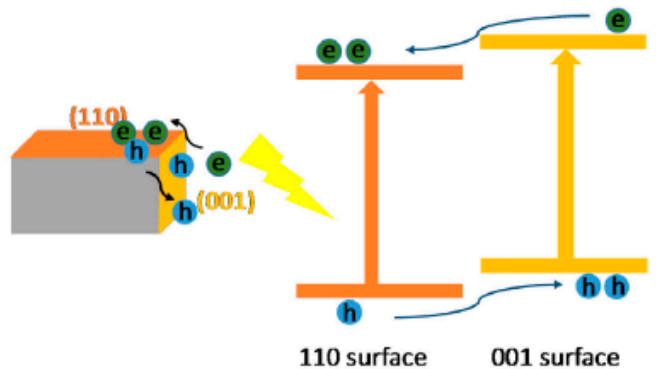

Figure 12. (a,b) Schematic illustrating the growth of $\mathrm{TiO}_{2}$ nanosheets at different conditions. (c) UV-vis images of the related samples. (d) Photocatalytic degradation efficiency of different catalysts for methyl orange. (e) Schematic demonstrating the migration of electrons and holes in the surface heterojunction.

Adapted with permission from Reference [74]. Copyright (2018) Elsevier.

\subsubsection{Z-Scheme Heterojunctions}

Z-scheme heterojunctions were constructed to overcome the limitation of the lower redox potential of the heterojunction systems. $[59,75]$ In general, the Z-scheme heterojunction is composed of two different semiconductors and an electron acceptor/donor pair. During the photocatalysis process, the photo-generated electrons/holes will transfer from the matrix semiconductor to the coupled semiconductor through the electron acceptor/donor pair or an electron mediator. As a result, the electrons/holes will accumulate on different semiconductors with higher redox potentiasl, and an effective spatial separation of electron-hole pairs is also realized. Up to now, the Z-scheme heterojunctions have been well developed, and various photocatalysts with well-designed Z-scheme heterojunctions have been invented for the wastewater treatment. [75] For example, Wu et al. [76] reported the fabrication of the $\mathrm{Ag}_{2} \mathrm{CO}_{3} / \mathrm{Ag} / \mathrm{AgNCO}$ composite photocatalyst via a simple in situ ion exchange method. The obtained composite photocatalyst possessed the Z-scheme heterojunction and exhibited a highly efficient degradation ratio of rhodamine $\mathrm{B}$ and the reduction of $\mathrm{Cr}$ (VI) under the driving of visible light. They proved that the significantly enhanced photocatalytic activity could be attributed to the low resistance for the interfacial charge transfer and desirable absorption capability. Recently, considering the relative high cost of the common used electron mediators (e.g., $\mathrm{Pt}, \mathrm{Ag}$, and $\mathrm{Au}$ ), a new generation of Z-heterojunctions without the electron mediators have been invented for 
wastewater treatment, which is named as the direct Z-scheme system [59]. For example, Lu et al. [77] synthesized a CuInS $2 / \mathrm{Bi}_{2} \mathrm{WO}_{6}$ composite catalyst with a direct $Z$-scheme heterojunction via the in situ hydrothermal growth of $\mathrm{Bi}_{2} \mathrm{WO}_{6}$ on the surface of $\mathrm{CuInS}_{2}$ networks. The obtained composite photocatalysts with an optimal Z-scheme exhibited a superior visible light degradation performance of the tetracycline hydrochloride in water than that of the pristine $\mathrm{CuInS}_{2}$ and $\mathrm{Bi}_{2} \mathrm{WO}_{6}$. The improved photocatalytic activity was attributed to the formed intimate interface contact, which ensured a good interfacial charge transfer ability (Figure 13).

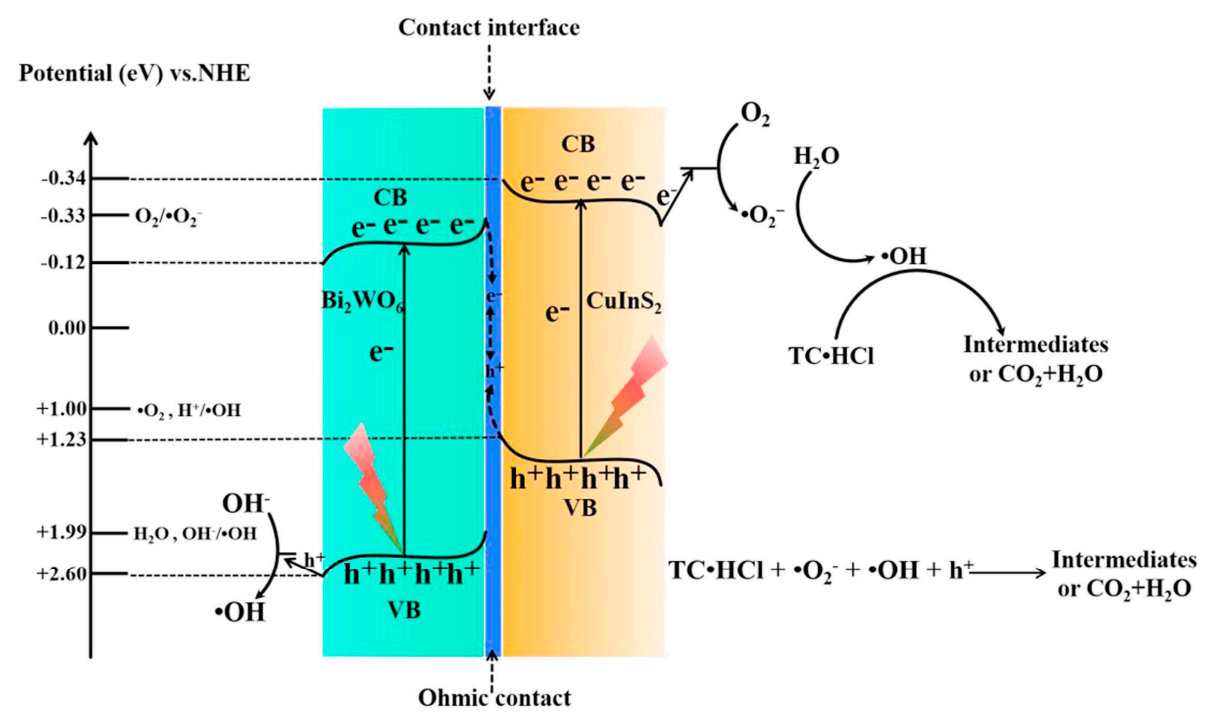

Figure 13. Schematic illustrating the interfacial electron transfer process and possible photocatalytic mechanism of $\mathrm{CuInS}_{2} / \mathrm{Bi}_{2} \mathrm{WO}_{6}$ with the Z-scheme heterojunction. Adapted with permission from Reference [77]. Copyright (2019) Elsevier.

\subsubsection{Semiconductor/Carbon Heterojunctions}

Carbonaceous nanomaterials have been widely employed for the design of novel photocatalysts due to their advantages of high surface area, good conductivity, and chemical stability. In general, the most commonly used carbonaceous materials for combining with semiconductors involves the carbon dots (CDs), carbon nanotubes (CNTs), and graphene [78].

The CDs as typical nanocarbon materials have been widely used to enhance the photocatalytic activity of semiconductors owing to their intriguing optical and electronic properties, low chemical toxicity, adjustable photoluminescence, and the distinct quantum effect [79]. For example, Long et al. [80] used carbon dots (CDs) to couple with the BiOI with highly exposed (001) facets to form a composition of CDs/BiOI. Furthermore, the obtained CDs/BiOI composite exhibited a greatly improved photocatalytic activity for the degradation of organic dyes in water. It has been proved that the incorporated CDs in the semiconductor formed a CDs/BiOI heterojunction, which was able to construct numerous electron surface trap sites and was beneficial for enhancing the visible light absorption range as well as the charge separation. Recently, Zhao et al. [81] reported the fabrication of carbon quantum dots (CQDs) $/ \mathrm{TiO}_{2}$ nanotubes (TNTs) composite via an improved hydrothermal method. The CQDs were incorporated on the surface of the TNTs, and played a vital role in improving the visible light photocatalytic performance of the composite. As shown in Figure 14, they demonstrated that there were three advantages for the formation of $\mathrm{CQDs} / \mathrm{TiO}_{2}$ : (i) the CQDs could effectively trap the photo-generated electrons from TNTs and suppress the recombination of electron-hole pairs, (ii) the up-conversion photoluminescence property of CQDs could further improve the visible light utilization efficiency of CQDs/TNTs, and (iii) the hetero-structure formed between the CQDs and the TNTs could prolong the life of the photogenerated electron and hole pairs. 


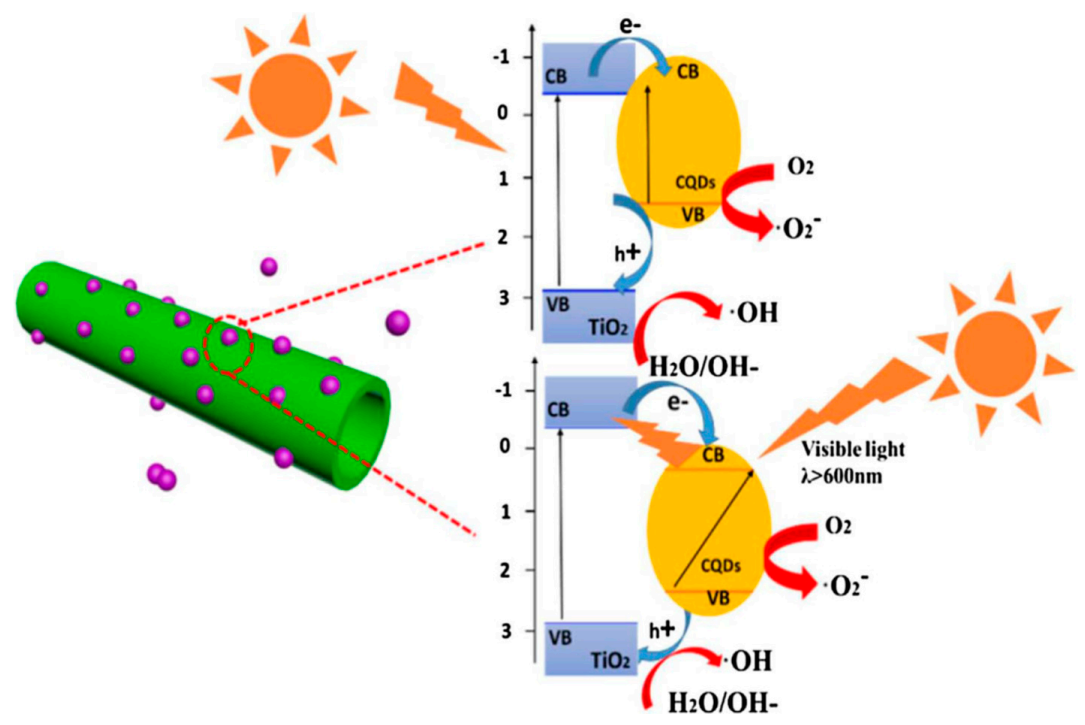

Figure 14. Schematic illustration indicating the photocatalysis mechanism of the CQDs/TNTs photocatalyst. Adapted with permission from Reference [81]. Copyright (2018) Elsevier.

CNTs are typical nanocarbon materials with highly $\mathrm{sp}^{2}$-ordered structures, and thus exhibit an excellent metallic conductivity, which could form a Schottky barrier junction between the CNT and semiconductors; as reported before, the Schottky barrier junction could effectively increase the recombination time of electron-hole pairs [78,82]. Moreover, CNTs could accept electrons in the composite system with semiconductors due to its large electron-storage capacity, which is beneficial for retarding or hindering the electron-hole recombination. As a result, a variety of semiconductor-CNT composite photocatalysts have been developed. For example, Miribangul et al. [83] prepared a $\mathrm{TiO}_{2} / \mathrm{CNT}$ composite via a simple hydrothermal method. The influence of the $\mathrm{CNT}$ concentration in the $\mathrm{TiO}_{2}-\mathrm{CNT}$ composites on their photocatalytic activity was investigated and the $0.3 \mathrm{wt} \% \mathrm{CNT}$ content in $\mathrm{TiO}_{2} / \mathrm{CNT}$ composite could offer the highest photocatalytic degradation of Sudan (I) in UV-vis light. Apart from the $\mathrm{TiO}_{2}$, some of the other semiconductors can also be employed to composite with CNT, such as the CNT/LaVO composite photocatalyst developed by $\mathrm{Xu}$ et al. [84]. As shown in Figure 15, with the presence of CNT, the photocatalytic activity of a CNT/LaVO 4 composite was greatly improved due to the synergistic effect between $\mathrm{CNT}$ and $\mathrm{LaVO}_{4}$, therefore the corresponding photocatalytic degradation rate of $\mathrm{CNT} / \mathrm{LaVO}_{4}$ composite for organic contaminant is 2 times that of pure $\mathrm{LaVO}_{4}$.

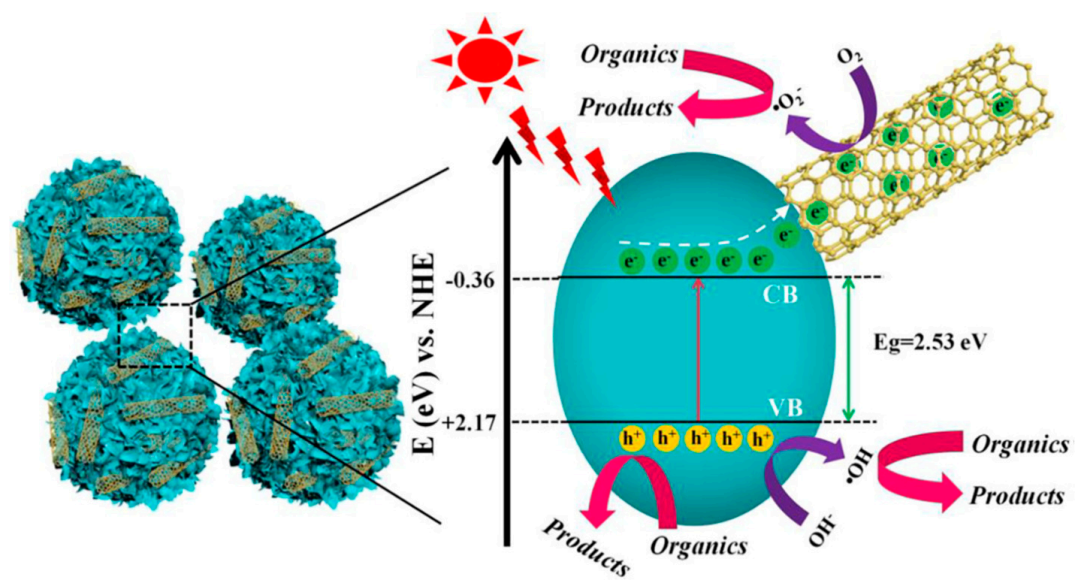

Figure 15. Schematic illustration indicating the reaction mechanism of the photocatalytic procedure of $\mathrm{CNT} / \mathrm{LaVO}_{4}$ composite catalyst. Adapted with permission from Reference [84]. Copyright (2019) Elsevier. 
Recently, graphene as a newly developed nanocarbon material has attracted numerous research attention in the area of photocatalysts due to its extraordinary physical properties, including superior charge transport ability, unique optical properties, high thermal conductivity, large specific surface area, and good mechanical strength $[78,85,86]$. Up to now, a myriad of attempts has been carried out to couple the graphene with various semiconductors to further improve their photocatalytic activity. According to the previous reports, the first graphene composite semiconductor for photocatalysis was prepared by Zhang and co-workers [87]. They fabricated a $\mathrm{TiO}_{2}$ (P25)-graphene composite with a chemically bonding structure via a one-step hydrothermal reaction. As reported, there are three contributions of the graphene for the photocatalytic activity: (i) enhancing the adsorption capacity of pollutants, (ii) extending light absorption range, and (iii) improving charge transportation and separation efficiency. As a result, the photodegradation of the obtained $\mathrm{TiO}_{2}$ (P25)-graphene composite for methylene blue was significantly improved, and was superior to that of the bare P25 and the commonly reported P25-CNTs composite. After that, numerous photocatalysts based on the composite graphene-semiconductors have been invented for the treatment of wastewater. Most recently, in order to overcome the limitation of the poor homogenous dispersion of graphene, as shown in Figure 16, Isari et al. [88] created a ternary nanocomposite catalyst (Fe-doped $\mathrm{TiO}_{2} / \mathrm{rGO}$ ) derived from Fe-doped $\mathrm{TiO}_{2}$ and reduced graphene oxide via a simple sol-gel method. They proved that the band gap of $\mathrm{Fe}-\mathrm{TiO}_{2} / \mathrm{rGO}$ could be significantly decreased compared with that of the pristine $\mathrm{TiO}_{2}$, and the obtained Fe-doped $\mathrm{TiO}_{2} / \mathrm{rGO}$ exhibited an effective decontamination performance for rhodamine $\mathrm{B}$ in water.

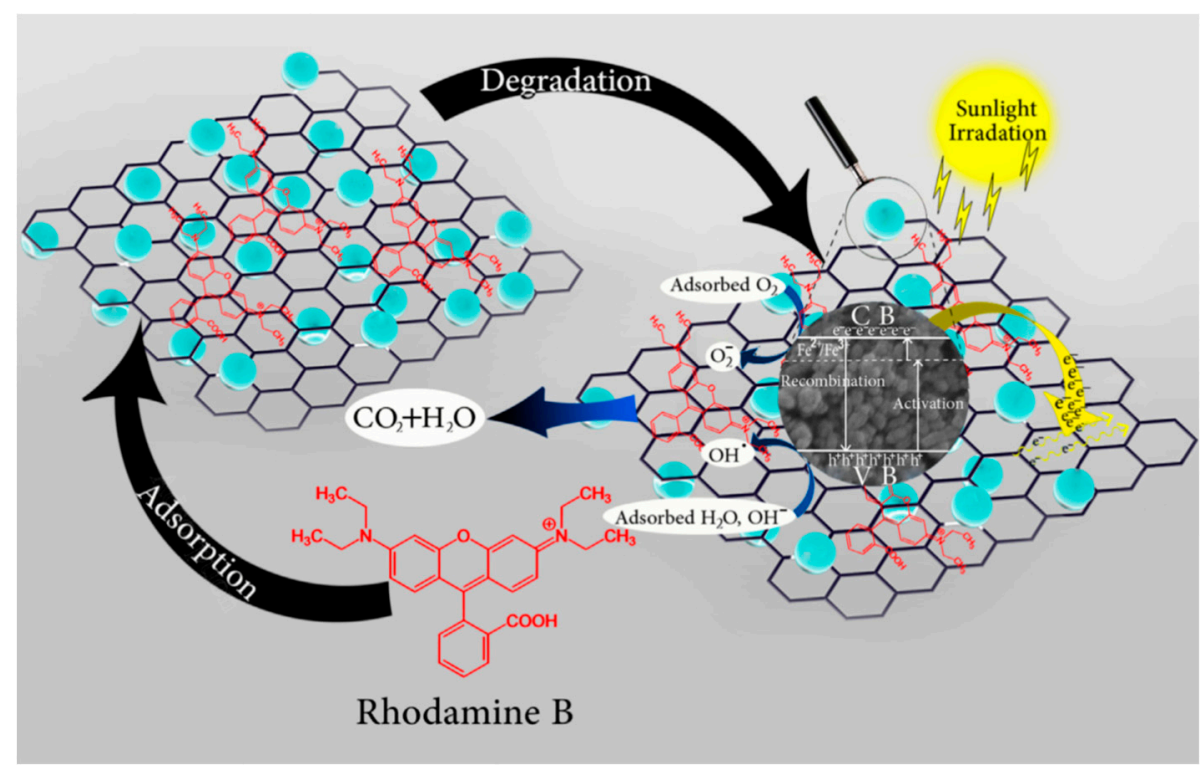

Figure 16. Schematic illustration demonstrating the photocatalytic mechanism of $\mathrm{Fe}-\mathrm{TiO}_{2} / \mathrm{rGO}$ catalyst for contaminant under solar irradiation. Adapted with permission from Reference [88]. Copyright (2018) Elsevier.

\section{Morphology Regulation of the Composite Photocatalysts}

Apart from the intrinsic characteristics of semiconductors, the corresponding catalysts with different morphologies may result in different photocatalytic activities and different application processes [89]. Recently, morphology modification of the photocatalysts have attracted more and more attention owing to further improvements in their application performance, not only for the photocatalytic performance but also for the application techniques. With this in mind, in this section we will briefly summarize the recent achievements of the composite photocatalysts with different morphologies of $0 \mathrm{D}, 1 \mathrm{D}, 2 \mathrm{D}$, and 3D materials. 


\subsection{Nanoparticles (OD)}

Generally, the OD materials are characterized as spherically shaped with nano-scaled dimensions. Nanoparticles as a typical 0D material have been widely used in the area of photocatalysis with the merits of large surface area, simple synthesis methods, and easy to be functionalized [90]. Up to now, several synthesis approaches have been invented, among which the sol-gel method, hydrothermal method, and solvothermal method could be the most-used techniques for the fabrication of $0 \mathrm{D}$ composite photocatalysts.

\subsubsection{Sol-Gel Method}

The sol-gel process is a commonly used and effective strategy for the preparation of various inorganic materials, especially for the metal oxides based on the corresponding precursors, and it has several merits including being low cost, processed at low-temperature, and the fine control of the product's chemical composition. Therefore, the sol-gel process is one of the most-used techniques for the preparation of composite semiconductor photocatalysts [58]. For example, Vaiano et al. [91] immobilized the $\mathrm{N}$-doped $\mathrm{TiO}_{2}$ nanoparticles (NPs) on glass spheres via the sol-gel method. Through regulating the synthesis conditions, and employing the Triton X-100 as the surface active agent, the obtained $\mathrm{N}$-doped $\mathrm{TiO}_{2} \mathrm{NPs}$ /glass spheres exhibited a good photocatalytic activity for methylene blue and eriochrome black-T in water under UV and visible light irradiation. Moreover, the composite catalyst was easy to be separated from the reaction mixture with a good durability. Recently, Chen et al. [92] prepared a Ni-Cu-Zn ferrite@SiO $\mathrm{S}_{2} @ \mathrm{TiO}_{2}$ composite via a simple sol-gel method. With the immobilization of Ag and magnetic ferrite, the composite photocatalysts exhibited comparatively good photodegradation performance for the methylene blue under a visible light source with lower power. Moreover, the composite catalysts can be easily separated using a magnet and can be reused well without significant loss of photocatalytic activity (Figure 17).
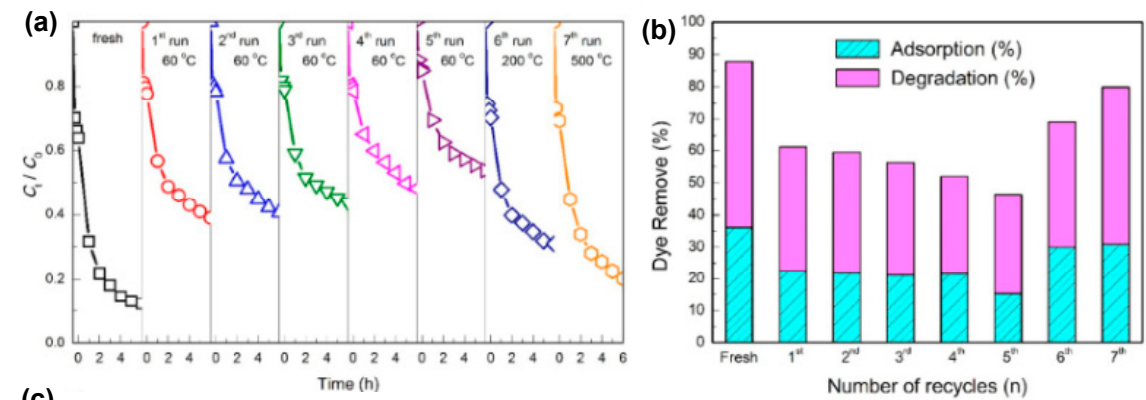

(c)

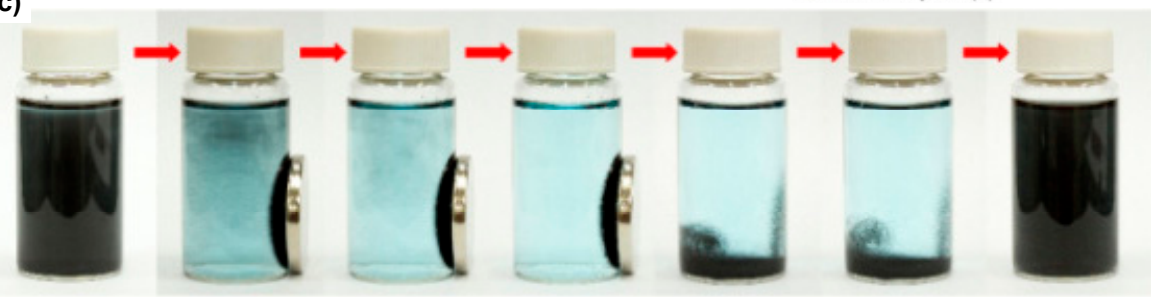

Figure 17. (a) The cycling test of the catalytic performance. (b) Dye removal capacity by adsorption and degradation for different cycles. (c) Digital photos demonstrating the recyclability by using an external magnetic field. Adapted with permission from Reference [92]. Copyright (2017) Elsevier.

\subsubsection{Hydrothermal Methods}

The hydrothermal method is a wet-chemistry method for synthesizing single crystals. Through the hydrothermal method, a great deal of crystalline phases that are not stable at the melting point can be obtained [93]. As a result, numerous semiconductor nanoparticles with different surface morphologies and compositions can also be prepared using the hydrothermal method. As a 
representative work, $\mathrm{Wu}$ et al. [94] fabricated the F-doped flower-like $\mathrm{TiO}_{2}$ nanoparticle on the surface of $\mathrm{Ti}$ via a low-temperature hydrothermal process. They reported that the presence of $\mathrm{HF}$ in water and the hydrothermal reaction time play an important role in the formation of the F-doped flower-like $\mathrm{TiO}_{2}$ nanostructures. Through regulating the synthesis parameters, the obtained F-doped $\mathrm{TiO}_{2}$ flower-like nanomaterials exhibited a superior photoelectrochemical activity for the photodegradation of organic pollutants compared with P-25. They also demonstrated that the improved photoelectrochemical activity of the F-doped $\mathrm{TiO}_{2}$ flower-like nanomaterials was mainly due to the larger surface area and the enhanced visible light harvest capacity. Additionally, magnetic composite photocatalysts can also be synthesized using the hydrothermal method, such as the magnetic $\mathrm{CoFe}_{2} \mathrm{O}_{4} / \mathrm{Ag} / \mathrm{Ag}_{3} \mathrm{VO}_{4}$ photocatalysts fabricated by Jing and co-workers [95]. During this study, the as-prepared $\mathrm{CoFe}_{2} \mathrm{O}_{4}$ nanoparticles were dispersed in the solutions with $\mathrm{AgNO}_{3}$ and $\mathrm{Na}_{3} \mathrm{VO}_{4}$, and the mixture suspensions were hydrothermally treated to prepare $\mathrm{CoFe}_{2} \mathrm{O}_{4} / \mathrm{Ag} / \mathrm{Ag}_{3} \mathrm{VO}_{4}$ composites. Through controlling the weight ratios of $\mathrm{CoFe}_{2} \mathrm{O}_{4}$ in the composite system, the optimal $\mathrm{CoFe}_{2} \mathrm{O}_{4} / \mathrm{Ag} / \mathrm{Ag}_{3} \mathrm{VO}_{4}$ composite exhibited significantly improved photocatalytic activity toward the degradation of various contaminants including methyl orange, tetracycline, and could even kill Escherichia coli solely under the driving of visible light. Moreover, with the advantage of having a good magnetic response property, the corresponding $\mathrm{CoFe}_{2} \mathrm{O}_{4} / \mathrm{Ag} / \mathrm{Ag}_{3} \mathrm{VO}_{4}$ composite could be facilely collected from the water by applying an extra magnetic field (Figure 18).
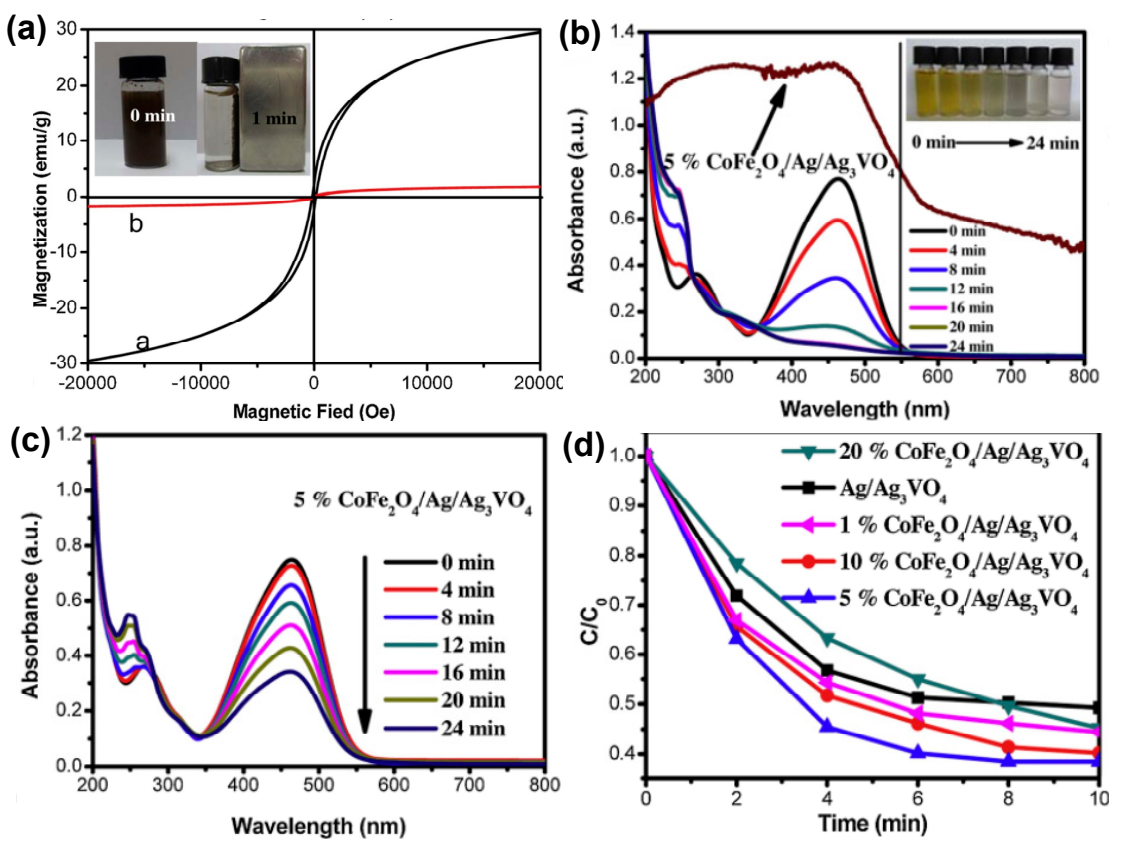

Figure 18. (a) Magnetic separation performance of the $\mathrm{CoFe}_{2} \mathrm{O}_{4} / \mathrm{Ag} / \mathrm{Ag}_{3} \mathrm{VO}_{4}$ composite. (b) The absorption spectra of methyl orange solutions over time in the presence of $\mathrm{CoFe}_{2} \mathrm{O}_{4} / \mathrm{Ag} / \mathrm{Ag}_{3} \mathrm{VO}_{4}$ (under visible light $\lambda \geq 440 \mathrm{~nm}$ ) and the UV-vis absorption spectrum of $\mathrm{CoFe}_{2} \mathrm{O}_{4} / \mathrm{Ag} / \mathrm{Ag}_{3} \mathrm{VO}_{4}$. (c) The evolution of the absorption spectra of methyl orange solutions over time in the presence of $\mathrm{CoFe}_{2} \mathrm{O}_{4} / \mathrm{Ag} / \mathrm{Ag}_{3} \mathrm{VO}_{4}$ (under visible light $\lambda \geq 550 \mathrm{~nm}$ ). (d) Photocatalytic degradation of tetracycline with different samples under visible light irradiation. Adapted with permission from Reference [95] Copyright (2016) Elsevier.

\subsection{Nanofibers/Nanorods (1D)}

Recently, nanofibrous photocatalysts have been intensively studied owing to their unique long aspect ratio, large surface area, and being easily functionalized. Up to now, various strategies had been developed to synthesize the 1D materials with different morphology like: wires, belts, rods, tubes, and rings $[61,89,96]$, among which, the hydrothermal method and electrospinning are the most-used techniques. Consequently, 
in this part, we present the development of composite semiconductors with nanofibrous morphology derived from the electrospinning method and hydrothermal method for the treatment of wastewater.

\subsubsection{Hydrothermal Method}

As mentioned above, the hydrothermal method is capable of synthesizing various inorganics with different morphologies, including the nanofibrous materials. For example, Yang et al. [97] once reported the fabrication of a novel $\mathrm{TiO}_{2}$ nanofibers with a shell of anatase nanocrystals based on the hydrothermal process. Actually, the whole fabrication process included three steps: First, the $\mathrm{H}_{2} \mathrm{Ti}_{3} \mathrm{O}_{7}$ nanofibers were obtained from the anatase $\mathrm{TiO}_{2}$ particles and $\mathrm{NaOH}$ solutions via hydrothermal method. After that, the as-prepared $\mathrm{H}_{2} \mathrm{Ti}_{3} \mathrm{O}_{7}$ nanofibers were treated using a dilute acid solution under certain hydrothermal condition to generate the anatase nanocrystal shell on the outside. Finally, the $\mathrm{H}_{2} \mathrm{Ti}_{3} \mathrm{O}_{7}$ phase was converted to $\mathrm{TiO}_{2}(\mathrm{~B})$ phase after a heat treatment while the anatase nanocrystal shell remained unchanged. Owing to the well-matched phase interfaces, which ensures the charge transfer across the interfaces, the recombination of electron-hole pairs was effectively suppressed and the corresponding photoactivity was significantly enhanced. Most importantly, they demonstrated that these nanofibrous photocatalysts possess specific surface areas similar to the commercial P25 powder, and the fibril morphology endowed them with a good recyclability from water, which is critically important in practical applications. Recently, our group also carried out a series of studies on the synthesis of nanofibrous photocatalysts via employing the hydrothermal method such as the bimetallic AuPd alloy nanoparticles deposited on $\mathrm{MoO}_{3}$ nanowires [98]. As shown in Figure 19, $\mathrm{MoO}_{3}$ nanowires were firstly prepared from Mo powder and $\mathrm{H}_{2} \mathrm{O}_{2}$ via the hydrothermal method. Then, the as-prepared $\mathrm{MoO}_{3}$ nanowires were used as the substrates to synthesize the $\mathrm{MoO}_{3} / \mathrm{Au}-\mathrm{Pd}$ bimetallic alloy nanowires via a simple chemical reduction method. As expected, the $\mathrm{MoO}_{3} / \mathrm{Au}-\mathrm{Pd}$ bimetallic alloy nanowires exhibited a good photocatalytic degradation performance for trichloroethylene (TCE) under the driving of visible light. Similarly, the composite nanowires could be easily separated from the reaction slurry in a short time after the reaction.

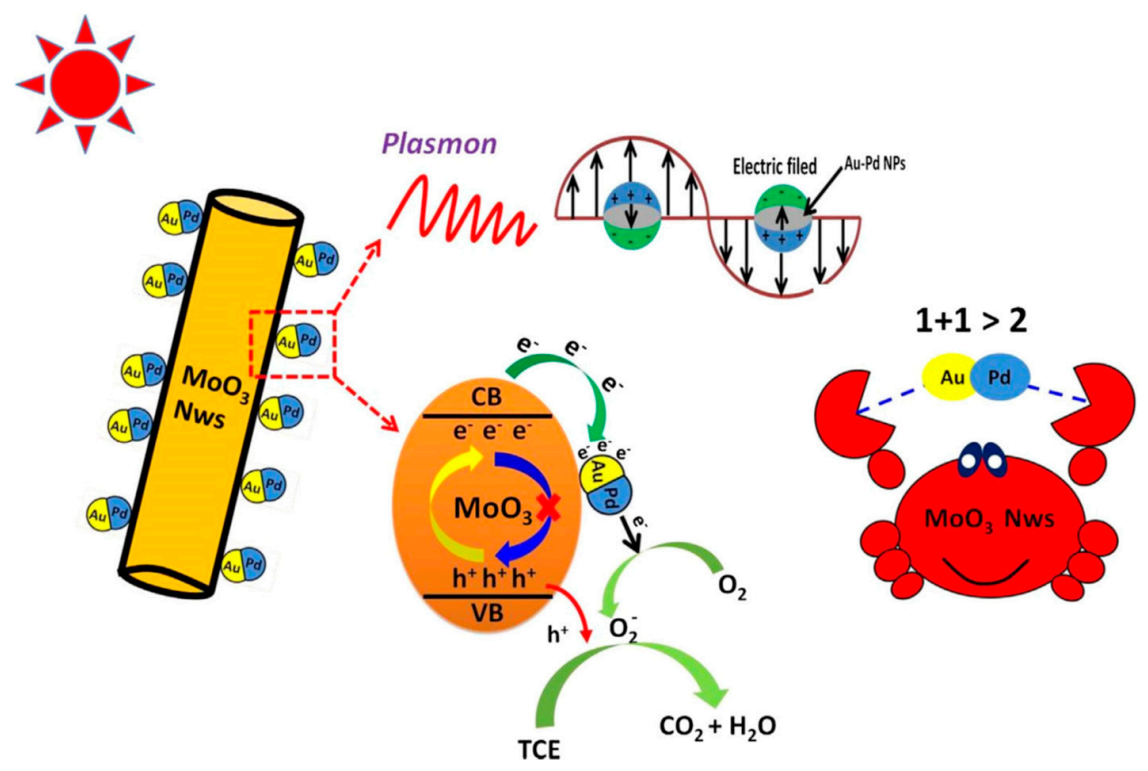

Figure 19. Schematic illustrating the band structure of $\mathrm{MoO}_{3} / \mathrm{Au}-\mathrm{Pd}$ composite photocatalyst and the possible reaction mechanism. Adapted with permission from Reference [98]. Copyright (2018) Elsevier.

\subsubsection{Electrospinning Method}

Electrospinning is considered as a promising way to synthesize nanofibers with several advantages, such as easy operation, low cost, and scalable [99-101]. In general, there are four major parts in an electrospinning device: (i) an electrical power supplier, (ii) a metallic needle, (iii) syringes with the 
polymer solution, and (iv) a conductive collector. Meanwhile, several process parameters, such as the polymer-based solution concentration, the viscosity of solution, the flow rate of the syringe driver, and the electric field power, could also be well-regulated to manipulate the morphology of fibers. During the electrospinning process, the solution is injected through a metallic needle via a syringe with a constant pump speed. At the same time, a voltage is applied on the metallic needle; therefore, the solution droplet will be charged, and then a Taylor cone will be generated when the electronic force is enough to overcome the surface tension. Following this, a liquid jet is formed between the grounded collector and the needle. The generated jets will be stretched by an electrostatic repulsion force until it reaches the collector; meanwhile, the solvent will rapidly evaporate during this process. Finally, the jets are solidified and the corresponding nanofibers are collected on the collector [100].

As for the applications of photocatalysis, high specific surface area is required to provide more active sites for the redox reaction. More specifically, electrospun nanofibers as forefront fibrous materials have attracted considerable research attention in the area of photocatalysis due to its several advantages of large surface area, extremely high aspect ratio, and ease of functionalization [102,103]. For example, Zhang et al. [104] reported the fabrication of a flexible and hierarchical mesoporous $\mathrm{TiO}_{2}$ nanoparticle $\left(\mathrm{TiO}_{2} \mathrm{NP}\right)$ modified $\mathrm{TiO}_{2}$ nanofiber composites via the combination of electrospinning and in situ polymerization method. At first, flexible $\mathrm{TiO}_{2}$ nanofibers were prepared via the electrospinning and the subsequently consuming process with the dopant of yttrium. After that, the as-prepared $\mathrm{TiO}_{2}$ nanofibers were used as a template for the incorporation of $\mathrm{TiO}_{2} \mathrm{NPs}$ by utilizing a bifunctional benzoxazine as the carrier through a calcination process in the $\mathrm{N}_{2}$ atmosphere. The as-prepared membranes exhibited remarkable photocatalytic activity towards organic dyes in water; moreover, it could be reused well via simply rinsing with water, and without time-consuming separation procedures owing to the long aspect ratio and good mechanical property of the composite nanofibers. In recent years, our group has carried out several works on the design of electrospun nanofibrous photocatalysts [105-109]. As a representative sample, a $\mathrm{BiOCl}_{0.3} / \mathrm{BiOBr}_{0.3} / \mathrm{BiOI}_{0.4} / \mathrm{PAN}$ composite fibrous catalyst was fabricated via combining the electrospinning and sol-gel method [109]. As shown in Figure 20, the obtained composite photocatalyst exhibited a typical fibril structure with a good uniformity, and the corresponding field emission transmission electron microscope (FE-TEM) image demonstrated a highly crystalline structure in the composite fibers with a clear lattice spacing relating to the (112) plane of $\mathrm{BiOCl}$, the (110) plane of $\mathrm{BiOBr}$, and the (200) plane of $\mathrm{BiOI}$; therefore, a heterojunction structure was generated via a close contact of the composite semiconductors. After a visible-light driven photocatalysis performance evaluation, it was found that the obtained $\mathrm{BiOCl}_{0.3} / \mathrm{BiOBr}_{0.3} / \mathrm{BiOI}_{0.4} / \mathrm{PAN}$ fiber displayed the highest photocatalytic degradation performance of TCE. Moreover, it was concluded that the improved visible-light driven photocatalytic activity is caused by the interfacial contact of a heterojunction and the inhibition of the recombination rate of the electron-hole pairs.
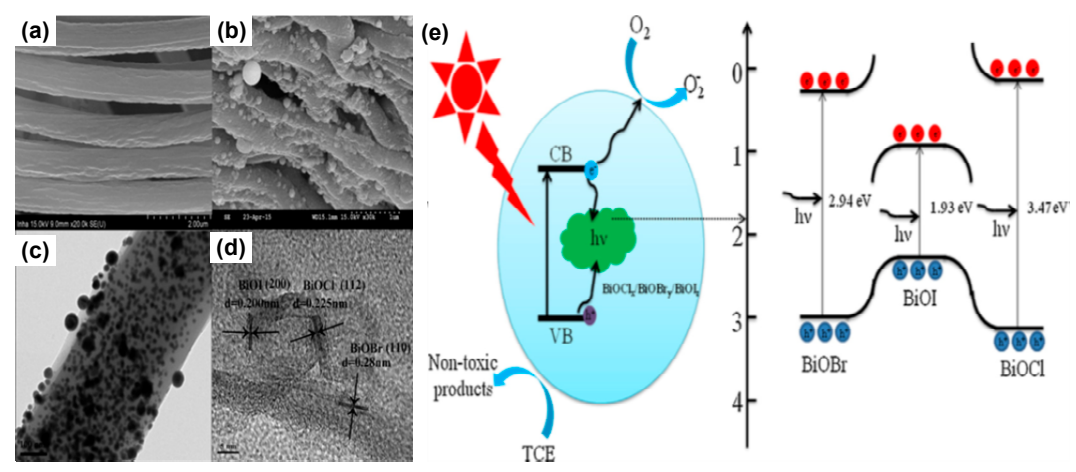

Figure 20. SEM image of pristine PAN fibers (a) and $\mathrm{BiOCl}_{\mathrm{x}} / \mathrm{BiOBr}_{\mathrm{y}} / \mathrm{BiOI}_{\mathrm{z}}$ composite fibers (b). (c) FE-TEM image of $\mathrm{BiOCl}_{x} / \mathrm{BiOBr}_{\mathrm{y}} / \mathrm{BiOI}_{z}$ fibers. (d) Lattice-resolved image for $\mathrm{BiOCl}_{\mathrm{x}} / \mathrm{BiOBr}_{\mathrm{y}} / \mathrm{BiOI}_{\mathrm{z}}$ nanofibers. (e) Schematic indicating the photocatalytic degradation of TCE. Adapted with permission from Reference [109]. Copyright (2016) Elsevier. 


\subsection{Nanosheets (2D)}

Semiconductor nanosheets are typical 2D nanomaterials and have attracted significant attention in the research area of photocatalysis for their larger surface area and tunable structures. Up to now, a great deal of semiconductor nanosheets have been synthesized via various strategies for different applications. The hydrothermal process is one of the most used strategies for the preparation of $2 \mathrm{D}$ semiconductor photocatalysts for the application of wastewater treatment [110]. Through the hydrothermal process, various nanosheets derived from a single semiconductor or multi-semiconductors could be synthesized. For example, Chen et al. [111] prepared $\mathrm{TiO}_{2}$-based nanosheets (TNS) via the alkaline hydrothermal treatment of commercial P25. They reported that the as-prepared TNS exhibited much higher specific surface area and much stronger adsorption for crystal violet molecules than the raw P25. Furthermore, the TNS could be effectively regenerated using a $\mathrm{H}_{2} \mathrm{O}_{2}$-assisted photocatalysis process, showing great potential for dealing with the high-chroma dye wastewater. Besides $\mathrm{TiO}_{2}$, various nanosheets derived from different semiconductors could also be fabricated using a hydrothermal process, such as the $\mathrm{WO}_{3}$ nanosheet $/ \mathrm{K}^{+} \mathrm{Ca}_{2} \mathrm{Nb}_{3} \mathrm{O}_{10}{ }^{-}$ultrathin nanosheet synthesized by Ma et al. [112] via a facile hydrothermal assembly of $\mathrm{WO}_{3}$ nanosheets and ultrathin $\mathrm{K}^{+} \mathrm{Ca}_{2} \mathrm{Nb}_{3} \mathrm{O}_{10}{ }^{-}$nanosheets. They demonstrated that the composite nanosheets possess $2 \mathrm{D} / 2 \mathrm{D}$ heterojunctions and display remarkably enhanced photocatalytic activity compared to the pristine $\mathrm{WO}_{3}$ and $\mathrm{K}^{+} \mathrm{Ca}_{2} \mathrm{Nb}_{3} \mathrm{O}_{10}{ }^{-}$nanosheets, which were mainly caused by the strongly coupled hetero-interfaces that provided more active sites for reactions and band structure. Additionally, some other methods, such as the solvothermal or photo-reduction methods, could also be employed for the preparation of composite nanosheets. For example, Wang et al. [113] fabricated the $\mathrm{Bi}_{12} \mathrm{O}_{15} \mathrm{Cl}_{6}$ nanosheets with a narrowed band gap via a simple and facile solvothermal method followed by a simple thermal treatment. The obtained $\mathrm{Bi}_{12} \mathrm{O}_{15} \mathrm{Cl}_{6}$ nanosheets exhibited a good photocatalytic degradation performance of bisphenol A solely under the driving of visible light, and the reaction rate of the composite nanosheets was 13.6 and 8.7 times faster than those of $\mathrm{BiOCl}$ and $\mathrm{TiO}_{2}$ (P25), respectively. In addition, the as-prepared $\mathrm{Bi1}_{2} \mathrm{O}_{15} \mathrm{Cl}_{6}$ nanosheets possessed good stability and recyclability during the photocatalytic process. As shown in Figure 21, our group recently developed a Pt/BiOI composite nanosheet via a photo-reduction method in ambient conditions [114], where the as-prepared $\mathrm{Pt} / \mathrm{BiOI}$ composites exhibited a flower-like structure and could effectively photocatalytically degrade the rhodamine $B$ and phenol under visible-light irradiation $(\lambda>420 \mathrm{~nm})$, where the degradation rate was superior to that of pure BiOI. Moreover, it was found that the content of $\mathrm{Pt}$ in the composite plays a vital important role on the photoactivity, and it was found that the optimal ratio of $\mathrm{Pt}$ to $\mathrm{BiOI}$ in the composite was 3\%. It was concluded that the enhanced photocatalytic activity of the $\mathrm{Pt} / \mathrm{BiOI}$ composite was caused by the superior electron transfer ability with the presence of an appropriate amount of Pt. 


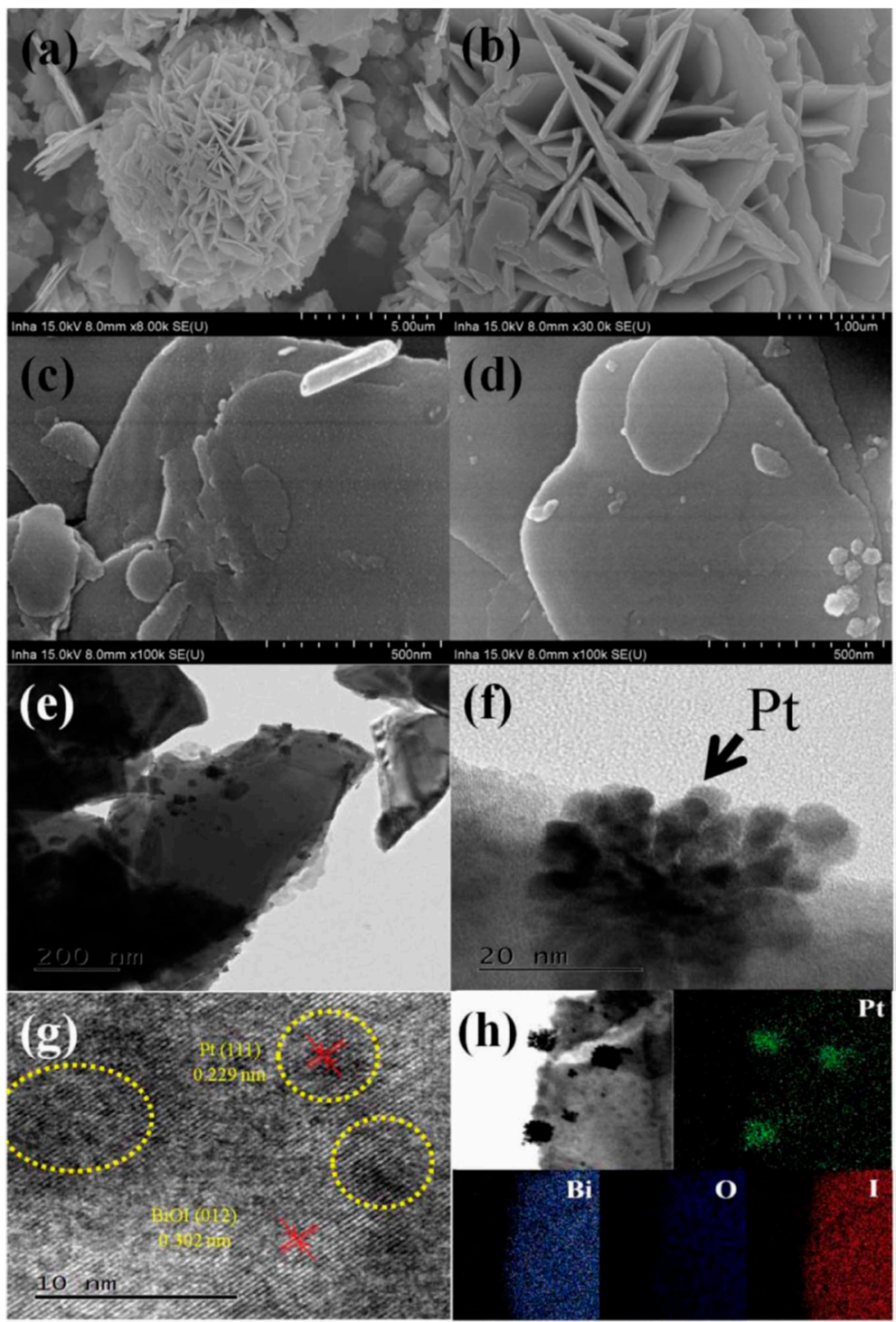

Figure 21. (a,b) SEM images of the obtained Pt/BiOI composite nanosheets. (c,d) HR-SEM images of $\mathrm{BiOI}$ nanosheets and $\mathrm{Pt} / \mathrm{BiOI}$ composite nanosheets, respectively. (e-g) HR-TEM images of Pt/BiOI composite nanosheets. (h) Element mappings of $\mathrm{Pt}, \mathrm{Bi}, \mathrm{O}$, and I for the $\mathrm{Pt} / \mathrm{BiOI}$ composite nanosheets. Adapted with permission from Reference [114]. Copyright (2017) Elsevier.

\subsection{Frameworks (3D)}

In recent years, there have been a great number of works reporting a new generation of composite photocatalysts with 3D frameworks [115]. Actually, the 3D photocatalysts with well-deigned frameworks show great advantages such as a large specific surface area, high adsorptive capacity, good structure stability, good mass transfer ability, and a large number of exposed active sites, which make them promising candidates for the highly efficient photodegradation of contaminants in water. In general, the 3D composite photocatalysts could be obtained via two approaches, which are to directly construct a photocatalyst with 3D frameworks (type I), or compositing the photocatalysts with a template with 3D frameworks (type II).

Through employing the commonly reported synthesis methods of various 3D frameworks, such as the sol-gel process, in situ assembly, and template methods, various 3D photocatalysts with different characteristics have be fabricated [116]. The sol-gel process is a well-developed strategy to synthesize aerogels, and some of the produced aerogels, such as the $\mathrm{SiO}_{2}$ aerogels, have been commercialized [117]. 
In general, there are two stages for the sol-gel process method: first, a precursor (e.g., metal alkoxide) is subjected to the hydrolysis and condensation reactions to form a wet gel, during which time, numerous networks are generated between the alkoxide groups; subsequently, the formed wet gels are sufficiently dried to obtain aerogels. As a matter of course, a photocatalytic aerogel can be obtained using a metal alkoxide precursor with an appropriate photocatalytic activity. For example, Dagan et al. [118] prepared a series of highly porous $\mathrm{TiO}_{2}$ aerogels via the sol-gel method and they also proved that the photocatalytic degradation performance of the $\mathrm{TiO}_{2}$ aerogels for organic contaminants is much better than that of a commercial $\mathrm{TiO}_{2}$ (P25). Besides, various photoactive metal oxides, metal silylamide, or their composite aerogels have been developed. However, due to the limitation of sol-gel processes, some metal oxides or metal chalcogenides are not able to be synthesized into aerogels, and the obtained aerogel photocatalysts usually suffer from low crystallinity. Therefore, a new generated strategy, namely an assembly method, has been invented to construct aerogels based on various nanoscale units with different morphologies and chemical properties. As reported before [116], there are three typical steps for the assembly process: (i) fabrication of the building blocks, (ii) preparing the dispersion of the building blocks with appropriated concentration, and (iii) solidified the suspension of building blocks to form a 3D monolith. Based on this principle, Heiligtag et al. [119] developed a 3D framework $\mathrm{Au}-\mathrm{TiO}_{2}$ photocatalysts with a preformed $\mathrm{TiO}_{2}$ nanoparticles as the blocking units without using any templates. Through modifying the surface of anatase $\mathrm{TiO}_{2}$ nanoparticles with trizma, the nanoparticles undergo an oriented attachment process during gelation and finally result in well-bonded networks. Moreover, based on the above-mentioned aerogel synthesis methods, various phototcatalytic aerogels can also be prepared via employing the preformed aerogels as the templates, such as a $\mathrm{C}_{3} \mathrm{~N}_{4}$ aerogel that was fabricated by Kailasam and co-workers [120] via preparing a $\mathrm{C}_{3} \mathrm{~N}_{4} / \mathrm{SiO}_{2}$ composite aerogel based on the sol-gel method at first, and then remove the $\mathrm{SiO}_{2}$ via treating the composite in $4 \mathrm{M}$ $\mathrm{NH}_{4} \mathrm{HF}_{2}$ (Figure 22).

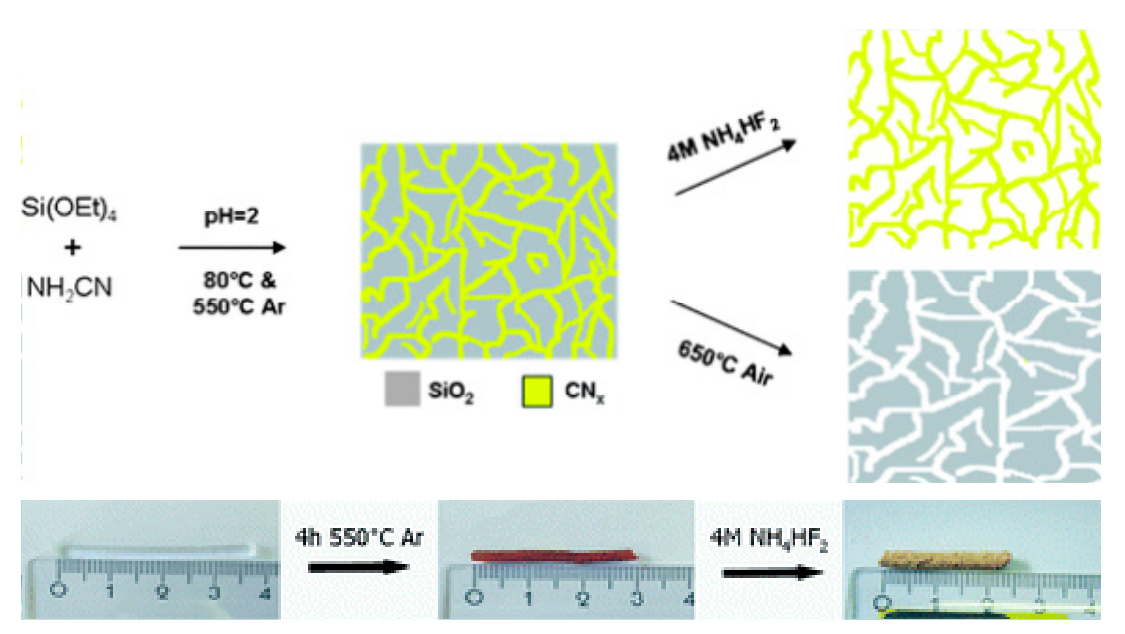

Figure 22. Schematic illustration indicating the synthesis process of porous carbon nitride and silica aerogels based on the sol-gel method and the digital photos of corresponding aerogels. Adapted with permission from Reference [120]. Copyright (2011) Royal Society of Chemistry.

As for the fabrication of type II 3D photocatalysts, an appropriate 3D porous substrate should be prepared before loading the active substance on its frameworks. Considering the requirements for high photoreactivity and good service performance, the aerogels/hydrogels derived from ceramics or carbon are mostly preferred. For example, Li et al. [121] fabricated a ternary magnetic composite of $\mathrm{Fe}_{3} \mathrm{O}_{4} @ \mathrm{TiO}_{2} / \mathrm{SiO}_{2}$ aerogel via combining the sol-gel process and a hydrothermal treatment. During the fabrication process, $\mathrm{Fe}_{3} \mathrm{O}_{4}$ microspheres were first synthesized via the hydrothermal method; after that, $\mathrm{Fe}_{3} \mathrm{O}_{4} @ \mathrm{TiO}_{2}$ core shell microspheres were fabricated via an in situ reaction method. The used $\mathrm{SiO}_{2}$ aerogel was derived from the industrial fly ash via a common sol-gel method. Finally, the as-prepared 
$\mathrm{Fe}_{3} \mathrm{O}_{4} @ \mathrm{TiO}_{2}$ core shell microspheres and $\mathrm{SiO}_{2}$ aerogel were combined via the hydrothermal method. According to their report, the obtained $\mathrm{Fe}_{3} \mathrm{O}_{4} @ \mathrm{TiO}_{2} / \mathrm{SiO}_{2}$ aerogel exhibited an enhanced photocatalytic activity for the degradation of rhodamine $\mathrm{B}$ dye under visible light irradiation, and the aerogel could be facilely collected after the reaction due to its good magnetic separation performance. Interestingly, as shown in Figure 23, Jiang et al. [122] recently developed a separation-free $\mathrm{PANI} / \mathrm{TiO}_{2} 3 \mathrm{D}$ hydrogel for the continuous photocatalytic degradation of various contaminants in water. In their studies, the PANI hydrogel with 3D frameworks was synthesized via the polymerization of aniline. During the gelling process, the $\mathrm{TiO}_{2}$ nanoparticles (P25) were incapsulated in the hydrogels. As a result, the obtained $\mathrm{PANI} / \mathrm{TiO}_{2}$ composite hydrogel exhibited an intriguing capacity for removing organic contaminants from water, which was mainly caused by the synergistic effect of adsorption enrichment of hydrogel and the in situ photocatalytic degradation of $\mathrm{TiO}_{2}$. Moreover, the presented separation-free characteristics in the obtained bulk materials indicate a good recyclability of the composite hydrogel.

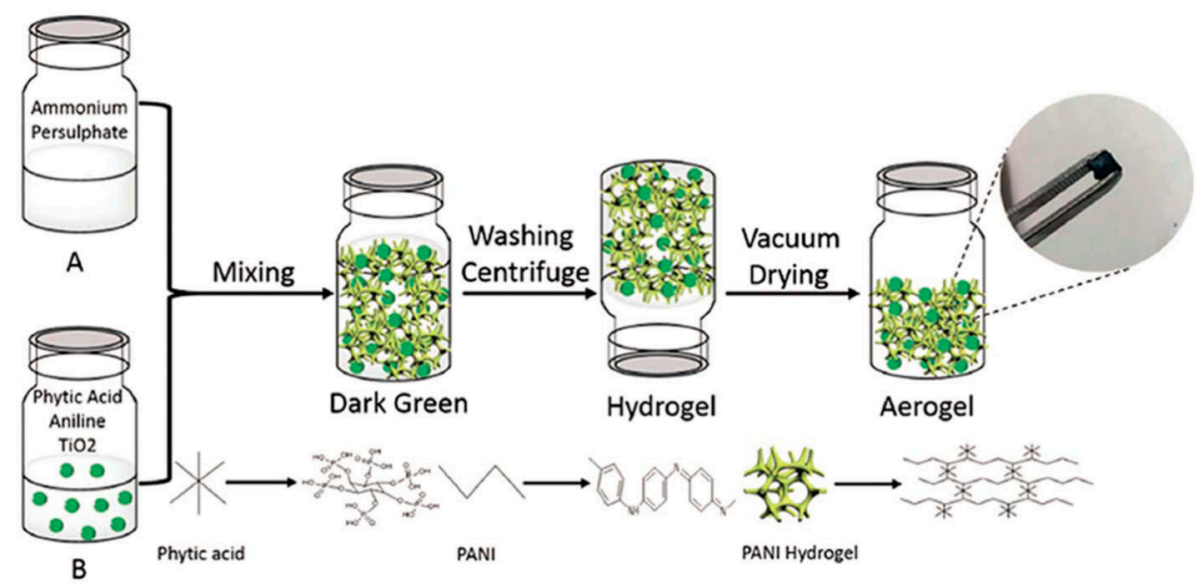

Figure 23. Schematic illustration demonstrating the synthesis process of the $3 \mathrm{D} \mathrm{PANI} / \mathrm{TiO}_{2}$ composite hydrogel. Adapted with permission from Reference [122]. Copyright (2015) Wiley.

\section{Summary and Perspectives}

In summary, in order to address the worldwide concerned issues of water pollutions, various photocatalysis processes based on different photocatalysts have been developed; meanwhile, numerous efforts have been made to further improve the photocatalytic activity of the catalysts based on the semiconducors. In this review, the recent progress in the development of composite semiconductor photocatalysts for wastewater treatment is presented, including the most-used strategies to narrow the band gap of semiconductors, to retard the recombination of the photo-generated electron-hole pairs, to enhance the visible light adsorption capacity, as well as to increase the reaction ratio between the photocatalysts and contaminants. Moreover, the composite catalyts with different morphologies and the corresponding photocatlytic performance were also summarized.

Although great development of the photocatalysis process has been obtained, there are still several problems yet to be addressed to further improve the practical application performance of the photocatalysis. Therefore, some plausible perspectives for the developing trend of composite photocatalysts for the wasterwater treatment are proposed based on the presented studies: (i) the existing synthesis methods are relative complex, high cost, and harmful to the environment to some degree, thus a more facile, highly efficent, and green method is anticipated; (ii) the mechanism of the composite semicondutor photocatalysts are still confusing and some of them are unpersuasive, therefore much more effort is needed for the basic studies of the catalytic mechanisms; and (iii) the practical use are limitted because the collection and reuse of the catalysts in water are still inconvenient due to their small size and poor mechanical property, therefore novel photocatalysts with easy collection property or new hybrid devices based on the composite of photocatalysts with selected 
substrates (e.g., polymers, metals) are proposed. Finally, we anticipate that this review can provide some useful guidance for the design of next generation of photocatlysts for the wastewater remediation.

Funding: This work was supported by the Technology Development Program (S2598148) funded by the Ministry of SMEs and Startups (MSS, Korea) and the Commercialization Promotion Agency for R\&D Outcomes (COMPA) funded by the Ministry of Science and ICT (MSIT) [2018_RND_002_0064, Development of $800 \mathrm{mAh} / \mathrm{g}$ pitch carbon coating.

Acknowledgments: This work was supported by the Technology Development Program (S2598148) funded by the Ministry of SMEs and Startups (MSS, Korea) and the Commercialization Promotion Agency for R\&D Outcomes (COMPA) funded by the Ministry of Science and ICT (MSIT) [2018_RND_002_0064, Development of $800 \mathrm{mAh} / \mathrm{g}$ pitch carbon coating.

Conflicts of Interest: The authors declare no conflict of interest.

\section{References}

1. Carpenter, S.R.; Caraco, N.F.; Correll, D.L.; Howarth, R.W.; Sharpley, A.N.; Smith, V.H. Nonpoint pollution of surface waters with phosphorus and nitrogen. Ecol. Appl. 1998, 8, 559-568. [CrossRef]

2. Jarup, L. Hazards of heavy metal contamination. Br. Med. Bull. 2003, 68, 167-182. [CrossRef] [PubMed]

3. Dudgeon, D.; Arthington, A.H.; Gessner, M.O.; Kawabata, Z.I.; Knowler, D.J.; Leveque, C.; Naiman, R.J.; Prieur-Richard, A.H.; Soto, D.; Stiassny, M.L.J.; et al. Freshwater biodiversity: Importance, threats, status and conservation challenges. Biol. Rev. 2006, 81, 163-182. [CrossRef] [PubMed]

4. Ribeiro, A.R.; Nunes, O.C.; Pereira, M.F.R.; Silva, A.M.T. An overview on the advanced oxidation processes applied for the treatment of water pollutants defined in the recently launched Directive 2013/39/EU. Environ. Int. 2015, 75, 33-51. [CrossRef] [PubMed]

5. Kolpin, D.W.; Furlong, E.T.; Meyer, M.T.; Thurman, E.M.; Zaugg, S.D.; Barber, L.B.; Buxton, H.T. Pharmaceuticals, hormones, and other organic wastewater contaminants in US streams, 1999-2000: A national reconnaissance. Environ. Sci. Technol. 2002, 36, 1202-1211. [CrossRef] [PubMed]

6. Schwarzenbach, R.P.; Escher, B.I.; Fenner, K.; Hofstetter, T.B.; Johnson, C.A.; von Gunten, U.; Wehrli, B. The challenge of micropollutants in aquatic systems. Science 2006, 313, 1072-1077. [CrossRef]

7. Radjenovic, J.; Sedlak, D.L. Challenges and opportunities for electrochemical processes as next-generation technologies for the treatment of contaminated water. Environ. Sci. Technol. 2015, 49, 11292-11302. [CrossRef]

8. Jiang, J.Q. The role of coagulation in water treatment. Curr. Opin. Chem. Eng. 2015, 8, 36-44. [CrossRef]

9. Lekang, O.I.; Bomo, A.M.; Svendsen, I. Biological lamella sedimentation used for wastewater treatment. Aquac. Eng. 2001, 24, 115-127. [CrossRef]

10. Ali, I. Water treatment by adsorption columns: Evaluation at ground level. Sep. Purif. Rev. 2014, 43, 175-205. [CrossRef]

11. Oe, T.; Koide, H.; Hirokawa, H.; Okukawa, K. Performance of membrane filtration system used for water treatment. Desalination 1996, 106, 107-113. [CrossRef]

12. Joss, A.; Zabczynski, S.; Gobel, A.; Hoffmann, B.; Loffler, D.; McArdell, C.S.; Ternes, T.A.; Thomsen, A.; Siegrist, H. Biological degradation of pharmaceuticals in municipal wastewater treatment: Proposing a classification scheme. Water Res. 2006, 40, 1686-1696. [CrossRef] [PubMed]

13. Mamba, G.; Mishra, A. Advances in magnetically separable photocatalysts: Smart, recyclable materials for water pollution mitigation. Catalysts 2016, 6, 34. [CrossRef]

14. Lee, S.Y.; Park, S.J. TiO 2 photocatalyst for water treatment applications. J. Ind. Eng. Chem. 2013, 19, 1761-1769. [CrossRef]

15. Van der Hoek, J.P.; Bertelkamp, C.; Verliefde, A.R.D.; Singhal, N. Drinking water treatment technologies in Europe: State of the art-challenges-research needs. J. Water Supply Res. Technol.-Aquac. 2014, 63, 124-130. [CrossRef]

16. Gogate, P.R.; Pandit, A.B. A review of imperative technologies for wastewater treatment I: Oxidation technologies at ambient conditions. Adv. Environ. Res. 2004, 8, 501-551. [CrossRef]

17. Oturan, M.A.; Aaron, J.J. Advanced oxidation processes in water/wastewater treatment: Principles and applications. a review. Crit. Rev. Environ. Sci. Technol. 2014, 44, 2577-2641. [CrossRef] 
18. Pelaez, M.; Nolan, N.T.; Pillai, S.C.; Seery, M.K.; Falaras, P.; Kontos, A.G.; Dunlop, P.S.M.; Hamilton, J.W.J.; Byrne, J.A.; O'Shea, K.; et al. A review on the visible light active titanium dioxide photocatalysts for environmental applications. Appl. Catal. B-Environ. 2012, 125, 331-349. [CrossRef]

19. Comninellis, C.; Kapalka, A.; Malato, S.; Parsons, S.A.; Poulios, L.; Mantzavinos, D. Advanced oxidation processes for water treatment: Advances and trends for R\&D. J. Chem. Technol. Biot. 2008, 83, 769-776.

20. Sansaniwal, S.K.; Sharma, V.; Mathur, J. Energy and exergy analyses of various typical solar energy applications: A comprehensive review. Renew. Sustain. Energy Rev. 2018, 82, 1576-1601. [CrossRef]

21. Mills, A.; Davies, R.H.; Worsley, D. Water-purification by semiconductor photocatalysis. Chem. Soc. Rev. 1993, 22, 417-425. [CrossRef]

22. Mills, A.; LeHunte, S. An overview of semiconductor photocatalysis. J. Photochem. Photobiol. A Chem. 1997, 108, 1-35. [CrossRef]

23. Fujishima, A.; Honda, K. Electrochemical photolysis of water at a semiconductor electrode. Nature 1972, 238, 37. [CrossRef] [PubMed]

24. Schneider, J.; Matsuoka, M.; Takeuchi, M.; Zhang, J.L.; Horiuchi, Y.; Anpo, M.; Bahnemann, D.W. Understanding $\mathrm{TiO}_{2}$ photocatalysis: Mechanisms and materials. Chem. Rev. 2014, 114, 9919-9986. [CrossRef] [PubMed]

25. Tong, H.; Ouyang, S.X.; Bi, Y.P.; Umezawa, N.; Oshikiri, M.; Ye, J.H. Nano-photocatalytic materials: Possibilities and challenges. Adv. Mater. 2012, 24, 229-251. [CrossRef] [PubMed]

26. An, H.Z.; Du, Y.; Wang, T.M.; Wang, C.; Hao, W.C.; Zhang, J.Y. Photocatalytic properties of BiOX $(\mathrm{X}=\mathrm{Cl}, \mathrm{Br}$, and I). Rare Metals 2008, 27, 243-250. [CrossRef]

27. Azeez, A.A.; Rhee, K.Y.; Park, S.J.; Hui, D. Epoxy clay nanocomposites-Processing, properties and applications: A review. Compos. Part B-Eng. 2013, 45, 308-320. [CrossRef]

28. Dhand, V.; Mittal, G.; Rhee, K.Y.; Park, S.J.; Hui, D. A short review on basalt fiber reinforced polymer composites. Compos. Part B-Eng. 2015, 73, 166-180. [CrossRef]

29. Chong, M.N.; Jin, B.; Chow, C.W.K.; Saint, C. Recent developments in photocatalytic water treatment technology: A review. Water Res. 2010, 44, 2997-3027. [CrossRef] [PubMed]

30. Ani, I.J.; Akpan, U.G.; Olutoye, M.A.; Hameed, B.H. Photocatalytic degradation of pollutants in petroleum refinery wastewater by $\mathrm{TiO}_{2}$ - and $\mathrm{ZnO}$-based photocatalysts: Recent development. J. Clean. Prod. 2018, 205, 930-954. [CrossRef]

31. Yu, Z.B.; Chen, X.Q.; Kang, X.D.; Xie, Y.P.; Zhu, H.Z.; Wang, S.L.; Ullah, S.; Ma, H.; Wang, L.Z.; Liu, G.; et al. Noninvasively modifying band structures of wide-bandgap metal oxides to boost photocatalytic activity. Adv. Mater. 2018, 30, 1706259. [CrossRef] [PubMed]

32. Choi, W.Y.; Termin, A.; Hoffmann, M.R. The role of metal ion dopants in quantum-sized $\mathrm{TiO}_{2}$ : Correlation between photoreativity and charge carrier recombination dynamics. J. Phys. Chem. 1994, 98, 13669-13679. [CrossRef]

33. Liu, G.; Wang, L.Z.; Yang, H.G.; Cheng, H.M.; Lu, G.Q. Titania-based photocatalysts-crystal growth, doping and heterostructuring. J. Mater. Chem. 2010, 20, 831-843. [CrossRef]

34. Zhu, J.F.; Deng, Z.G.; Chen, F.; Zhang, J.L.; Chen, H.J.; Anpo, M.; Huang, J.Z.; Zhang, L.Z. Hydrothermal doping method for preparation of $\mathrm{Cr}^{3+}-\mathrm{TiO}_{2}$ photocatalysts with concentration gradient distribution of $\mathrm{Cr}^{3+}$. Appl. Catal. B-Environ. 2006, 62, 329-335. [CrossRef]

35. Dvoranova, D.; Brezova, V.; Mazur, M.; Malati, M.A. Investigations of metal-doped titanium dioxide photocatalysts. Appl. Catal. B-Environ. 2002, 37, 91-105. [CrossRef]

36. Bouras, P.; Stathatos, E.; Lianos, P. Pure versus metal-ion-doped nanocrystalline titania for photocatalysis. Appl. Catal. B-Environ. 2007, 73, 51-59. [CrossRef]

37. Devi, L.G.; Kottam, N.; Murthy, B.N.; Kumar, S.G. Enhanced photocatalytic activity of transition metal ions $\mathrm{Mn}^{2+}, \mathrm{Ni}^{2+}$ and $\mathrm{Zn}^{2+}$ doped polycrystalline titania for the degradation of Aniline Blue under UV/solar light. J. Mol. Catal. A Chem. 2010, 328, 44-52. [CrossRef]

38. Serpone, N. Is the band gap of pristine $\mathrm{TiO}_{2}$ narrowed by anion- and cation-doping of titanium dioxide in second-generation photocatalysts? J. Phys. Chem. B 2006, 110, 24287-24293. [CrossRef]

39. Kudo, A.; Niishiro, R.; Iwase, A.; Kato, H. Effects of doping of metal cations on morphology, activity, and visible light response of photocatalysts. Chem. Phys. 2007, 339, 104-110. [CrossRef]

40. Chen, J.H.; Yao, M.S.; Wang, X.L. Investigation of transition metal ion doping behaviors on $\mathrm{TiO}_{2}$ nanoparticles. J. Nanopart. Res. 2008, 10, 163-171. [CrossRef] 
41. Dunnill, C.W.; Parkin, I.P. Nitrogen-doped $\mathrm{TiO}_{2}$ thin films: Photocatalytic applications for healthcare environments. Dalton Trans. 2011, 40, 1635-1640. [CrossRef] [PubMed]

42. Asahi, R.; Morikawa, T.; Irie, H.; Ohwaki, T. Nitrogen-doped titanium dioxide as visible-light-sensitive photocatalyst: Designs, developments, and prospects. Chem. Rev. 2014, 114, 9824-9852. [CrossRef] [PubMed]

43. Asahi, R.; Morikawa, T.; Ohwaki, T.; Aoki, K.; Taga, Y. Visible-light photocatalysis in nitrogen-doped titanium oxides. Science 2001, 293, 269-271. [CrossRef] [PubMed]

44. Kitano, M.; Funatsu, K.; Matsuoka, M.; Ueshima, M.; Anpo, M. Preparation of nitrogen-substituted TiO thin film photocatalysts by the radio frequency magnetron sputtering deposition method and their photocatalytic reactivity under visible light irradiation. J. Phys. Chem. B 2006, 110, 25266-25272. [CrossRef] [PubMed]

45. Salah, N.; Hameed, A.; Aslam, M.; Abdel-Wahab, M.S.; Babkair, S.S.; Bahabri, F.S. Flow controlled fabrication of $\mathrm{N}$ doped $\mathrm{ZnO}$ thin films and estimation of their performance for sunlight photocatalytic decontamination of water. Chem. Eng. J. 2016, 291, 115-127. [CrossRef]

46. Mikkelsen, N.J.; Pedersen, J.; Straede, C.A. Ion implantation-The job coater's supplement to coating techniques. Surf. Coat. Technol. 2002, 158, 42-47. [CrossRef]

47. Tang, G.Z.; Li, J.L.; Sun, M.R.; Ma, X.X. Fabrication of nitrogen-doped $\mathrm{TiO}_{2}$ layer on titanium substrate. Appl. Surf. Sci. 2009, 255, 9224-9229. [CrossRef]

48. Song, X.Y.; Li, W.Q.; He, D.; Wu, H.Y.; Ke, Z.J.; Jiang, C.Z.; Wang, G.M.; Xiao, X.H. The “Midas Touch" transformation of $\mathrm{TiO}_{2}$ nanowire arrays during visible light photoelectrochemical performance by carbon/nitrogen coimplantation. Adv. Energy Mater. 2018, 8, 1800165. [CrossRef]

49. Chen, X.; Mao, S.S. Titanium dioxide nanomaterials: Synthesis, properties, modifications, and applications. Chem. Rev. 2007, 107, 2891-2959. [CrossRef]

50. Lee, S.Y.; Park, J.; Joo, H. Visible light-sensitized photocatalyst immobilized on beads by CVD in a fluidizing bed. Sol. Energy Mater. Sol. Cell 2006, 90, 1905-1914. [CrossRef]

51. Kafizas, A.; Crick, C.; Parkin, I.P. The combinatorial atmospheric pressure chemical vapour deposition (cAPCVD) of a gradating substitutional/interstitial N-doped anatase $\mathrm{TiO}_{2}$ thin-film; UVA and visible light photocatalytic activities. J. Photochem. Photobiol. A Chem. 2010, 216, 156-166. [CrossRef]

52. Youssef, L.; Leoga, A.J.K.; Roualdes, S.; Bassil, J.; Zakhour, M.; Rouessac, V.; Ayral, A.; Nakhl, M. Optimization of $\mathrm{N}$-doped $\mathrm{TiO}_{2}$ multifunctional thin layers by low frequency PECVD process. J. Eur. Ceram. Soc. 2017, 37, 5289-5303. [CrossRef]

53. George, S.M. Atomic layer deposition: An Overview. Chem. Rev. 2010, 110, 111-131. [CrossRef]

54. Vilhunen, S.H.; Sillanpaa, M.E.T. Atomic layer deposited (ALD) $\mathrm{TiO}_{2}$ and $\mathrm{TiO}_{2-\mathrm{x}} \mathrm{N}_{\mathrm{x}}$ thin film photocatalysts in salicylic acid decomposition. Water Sci. Technol. 2009, 60, 2471-2475. [CrossRef]

55. Pore, V.; Heikkila, M.; Ritala, M.; Leskela, M.; Areva, S. Atomic layer deposition of $\mathrm{TiO}_{2-\mathrm{x}} \mathrm{N}_{\mathrm{x}}$ thin films for photocatalytic applications. J. Photochem. Photobiol. A Chem. 2006, 177, 68-75. [CrossRef]

56. Lee, A.; Libera, J.A.; Waldman, R.Z.; Ahmed, A.; Avila, J.R.; Elam, J.W.; Darling, S.B. Conformal nitrogen-doped $\mathrm{TiO}_{2}$ photocatalytic coatings for sunlight-activated membranes. Adv. Sustain. Syst. 2017, 1, 1600041. [CrossRef]

57. Albrbar, A.J.; Djokic, V.; Bjelajac, A.; Kovac, J.; Cirkovic, J.; Mitric, M.; Janackovic, D.; Petrovic, R. Visible-light active mesoporous, nanocrystalline N,S-doped and co-doped titania photocatalysts synthesized by non-hydrolytic sol-gel route. Ceram. Int. 2016, 42, 16718-16728. [CrossRef]

58. Rajoriya, S.; Bargole, S.; George, S.; Saharan, V.K.; Gogate, P.R.; Pandit, A.B. Synthesis and characterization of samarium and nitrogen doped $\mathrm{TiO}_{2}$ photocatalysts for photo-degradation of 4-acetamidophenol in combination with hydrodynamic and acoustic cavitation. Sep. Purif. Technol. 2019, 209, 254-269. [CrossRef]

59. Low, J.; Yu, J.; Jaroniec, M.; Wageh, S.; Al-Ghamdi, A.A. Heterojunction photocatalysts. Adv. Mater. 2017, 29, 1601694. [CrossRef]

60. Baek, J.H.; Kim, B.J.; Han, G.S.; Hwang, S.W.; Kim, D.R.; Cho, I.S.; Jung, H.S. BiVO $\mathrm{Bi}_{4} / \mathrm{WO}_{3} / \mathrm{SnO}_{2}$ Double-heterojunction photoanode with enhanced charge separation and visible-transparency for bias-free solar water-splitting with a perovskite solar cell. ACS Appl. Mater. Interfaces 2017, 9, 1479-1487. [CrossRef]

61. Han, H.S.; Han, G.S.; Kim, J.S.; Kim, D.H.; Hong, J.S.; Caliskan, S.; Jung, H.S.; Cho, I.S.; Lee, J.K. Indium-tin-oxide nanowire array based $\mathrm{CdSe} / \mathrm{CdS} / \mathrm{TiO}_{2}$ one-dimensional heterojunction photoelectrode for enhanced solar hydrogen production. ACS Sustain. Chem. Eng. 2016, 4, 1161-1168. [CrossRef]

62. Yu, J.C.; Yu, J.G.; Ho, W.K.; Zhang, L.Z. Preparation of highly photocatalytic active nano-sized $\mathrm{TiO}_{2}$ particles via ultrasonic irradiation. Chem. Commun. 2001, 1942-1943. [CrossRef] 
63. Uddin, M.T.; Nicolas, Y.; Olivier, C.; Toupance, T.; Servant, L.; Muller, M.M.; Kleebe, H.J.; Ziegler, J.; Jaegermann, W. Nanostructured $\mathrm{SnO}_{2}-\mathrm{ZnO}$ heterojunction photocatalysts showing enhanced photocatalytic activity for the degradation of organic dyes. Inorg. Chem. 2012, 51, 7764-7773. [CrossRef]

64. Shirmardi, A.; Teridi, M.A.M.; Azimi, H.R.; Basirun, W.J.; Jamali-Sheini, F.; Yousefi, R. Enhanced photocatalytic performance of ZnSe/PANI nanocomposites for degradation of organic and inorganic pollutants. Appl. Surf. Sci. 2018, 462, 730-738. [CrossRef]

65. Lee, C.H.; Lee, G.H.; van der Zande, A.M.; Chen, W.C.; Li, Y.L.; Han, M.Y.; Cui, X.; Arefe, G.; Nuckolls, C.; Heinz, T.F.; et al. Atomically thin p-n junctions with van der Waals heterointerfaces. Nat. Nanotechnol. 2014, 9, 676-681. [CrossRef]

66. Kawazoe, H.; Yanagi, H.; Ueda, K.; Hosono, H. Transparent p-type conducting oxides: Design and fabrication of p-n heterojunctions. MRS Bull. 2000, 25, 28-36. [CrossRef]

67. Lu, M.X.; Shao, C.L.; Wang, K.X.; Lu, N.; Zhang, X.; Zhang, P.; Zhang, M.Y.; Li, X.H.; Liu, Y.C. $\mathrm{p}-\mathrm{MoO}_{3}$ Nanostructures $/ \mathrm{n}-\mathrm{TiO}_{2}$ nanofiber heterojunctions: Controlled fabrication and enhanced photocatalytic properties. ACS Appl. Mater. Interfaces 2014, 6, 9004-9012. [CrossRef]

68. Zhang, L.P.; Jaroniec, M. Toward designing semiconductor-semiconductor heterojunctions for photocatalytic applications. Appl. Surf. Sci. 2018, 430, 2-17. [CrossRef]

69. Wen, X.J.; Niu, C.G.; Zhang, L.; Zeng, G.M. Novel p-n heterojunction BiOI/CeO 2 photocatalyst for wider spectrum visible-light photocatalytic degradation of refractory pollutants. Dalton Trans. 2017, 46, 4982-4993. [CrossRef]

70. Zhang, Y.; Park, S.J. Formation of hollow $\mathrm{MoO}_{3} / \mathrm{SnS}_{2}$ heterostructured nanotubes for efficient light-driven hydrogen peroxide production. J. Mater. Chem. A 2018, 6, 20304-20312. [CrossRef]

71. Wei, Z.D.; Zhao, Y.; Fan, F.T.; Li, C. The property of surface heterojunction performed by crystal facets for photogenerated charge separation. Comp. Mater. Sci. 2018, 153, 28-35. [CrossRef]

72. Yu, J.G.; Low, J.X.; Xiao, W.; Zhou, P.; Jaroniec, M. Enhanced Photocatalytic $\mathrm{CO}_{2}$-Reduction Activity of Anatase $\mathrm{TiO}_{2}$ by Coexposed $\{001\}$ and $\{101\}$ Facets. J. Am. Chem. Soc. 2014, 136, 8839-8842. [CrossRef]

73. Gao, S.J.; Wang, W.; Ni, Y.R.; Lu, C.H.; Xu, Z.Z. Facet-dependent photocatalytic mechanisms of anatase $\mathrm{TiO}_{2}$ : A new sight on the self-adjusted surface heterojunction. J. Alloys Compd. 2015, 647, 981-988. [CrossRef]

74. Lu, J.; Wu, J.; Xu, W.X.; Cheng, H.Q.; Qi, X.M.; Li, Q.W.; Zhang, Y.A.; Guan, Y.; Ling, Y.; Zhang, Z. Room temperature synthesis of tetragonal BiOI photocatalyst with surface heterojunction between (001) facets and (110) facets. Mater. Lett. 2018, 219, 260-264. [CrossRef]

75. Li, H.J.; Tu, W.G.; Zhou, Y.; Zou, Z.G. Z-scheme photocatalytic systems for promoting photocatalytic performance: Recent progress and future challenges. Adv. Sci. 2016, 3, 12. [CrossRef]

76. Wu, X.S.; Hu, Y.D.; Wang, Y.; Zhou, Y.S.; Han, Z.H.; Jin, X.L.; Chen, G. In-situ synthesis of Z-scheme $\mathrm{Ag}_{2} \mathrm{CO}_{3} / \mathrm{Ag} / \mathrm{AgNCO}$ heterojunction photocatalyst with enhanced stability and photocatalytic activity. Appl. Surf. Sci. 2019, 464, 108-114. [CrossRef]

77. Lu, X.Y.; Che, W.J.; Hu, X.F.; Wang, Y.; Zhang, A.T.; Deng, F.; Luo, S.L.; Dionysiou, D.D. The facile fabrication of novel visible-light-driven $\mathrm{Z}$-scheme $\mathrm{CuInS}_{2} / \mathrm{Bi}_{2} \mathrm{WO}_{6}$ heterojunction with intimate interface contact by in situ hydrothermal growth strategy for extraordinary photocatalytic performance. Chem. Eng. J. 2019, 356, 819-829. [CrossRef]

78. Leary, R.; Westwood, A. Carbonaceous nanomaterials for the enhancement of $\mathrm{TiO}_{2}$ photocatalysis. Carbon 2011, 49, 741-772. [CrossRef]

79. Li, J.; Liu, K.; Xue, J.; Xue, G.; Sheng, X.; Wang, H.; Huo, P.; Yan, Y. CQDS preluded carbon-incorporated 3D burger-like hybrid $\mathrm{ZnO}$ enhanced visible-light-driven photocatalytic activity and mechanism implication. J. Catal. 2019, 369, 450-461. [CrossRef]

80. Long, B.; Huang, Y.C.; Li, H.B.; Zhao, F.Y.; Rui, Z.B.; Liu, Z.L.; Tong, Y.X.; Ji, H.B. Carbon Dots Sensitized BiOI with Dominant $\{001\}$ Facets for superior photocatalytic performance. Ind. Eng. Chem. Res. 2015, 54, 12788-12794. [CrossRef]

81. Zhao, F.F.; Rong, Y.F.; Wan, J.M.; Hu, Z.W.; Peng, Z.Q.; Wang, B. High photocatalytic performance of carbon quantum dots/TNTs composites for enhanced photogenerated charges separation under visible light. Catal. Today 2018, 315, 162-170. [CrossRef]

82. Di, J.; Li, S.X.; Zhao, Z.F.; Huang, Y.C.; Jia, Y.; Zheng, H.J. Biomimetic CNT@TiO 2 composite with enhanced photocatalytic properties. Chem. Eng. J. 2015, 281, 60-68. [CrossRef] 
83. Miribangul, A.; Ma, X.L.; Zeng, C.; Zou, H.; Wu, Y.H.; Fan, T.P.; Su, Z. Synthesis of TiO 2 /CNT Composites and its photocatalytic activity toward sudan (I) degradation. Photochem. Photobiol. 2016, 92, 523-527. [CrossRef]

84. Xu, Y.G.; Liu, J.; Xie, M.; Jing, L.Q.; Xu, H.; She, X.J.; Li, H.M.; Xie, J.M. Construction of novel CNT $/ \mathrm{LaVO}_{4}$ nanostructures for efficient antibiotic photodegradation. Chem. Eng. J. 2019, 357, 487-497. [CrossRef]

85. Wang, Y.J.; Shi, R.; Lin, J.; Zhu, Y.F. Significant photocatalytic enhancement in methylene blue degradation of $\mathrm{TiO}_{2}$ photocatalysts via graphene-like carbon in situ hybridization. Appl. Catal. B-Environ. 2010, 100, 179-183. [CrossRef]

86. Mamaghani, A.H.; Haghighat, F.; Lee, C.-S. Hydrothermal/solvothermal synthesis and treatment of $\mathrm{TiO}_{2}$ for photocatalytic degradation of air pollutants: Preparation, characterization, properties, and performance. Chemosphere 2019, 219, 804-825. [CrossRef]

87. Zhang, H.; Lv, X.J.; Li, Y.M.; Wang, Y.; Li, J.H. P25-Graphene composite as a high performance photocatalyst. ACS Nano 2010, 4, 380-386. [CrossRef]

88. Isari, A.A.; Payan, A.; Fattahi, M.; Jorfi, S.; Kakavandi, B. Photocatalytic degradation of rhodamine B and real textile wastewater using $\mathrm{Fe}$-doped $\mathrm{TiO}_{2}$ anchored on reduced graphene oxide $\left(\mathrm{Fe}-\mathrm{TiO}_{2} / \mathrm{rGO}\right)$ : Characterization and feasibility, mechanism and pathway studies. Appl. Surf. Sci. 2018, 462, 549-564. [CrossRef]

89. Nasr, M.; Eid, C.; Habchi, R.; Miele, P.; Bechelany, M. Recent progress on titanium dioxide nanomaterials for photocatalytic applications. ChemSusChem 2018, 11, 3023-3047. [CrossRef]

90. Giberman, D. Against zero-dimensional material objects (and other bare particulars). Philos. Stud. 2012, 160, 305-321. [CrossRef]

91. Vaiano, V.; Sacco, O.; Sannino, D.; Ciambelli, P. Nanostructured N-doped $\mathrm{TiO}_{2}$ coated on glass spheres for the photocatalytic removal of organic dyes under UV or visible light irradiation. Appl. Catal. B-Environ. 2015, 170, 153-161. [CrossRef]

92. Chen, C.C.; Jaihindh, D.; Hu, S.H.; Fu, Y.P. Magnetic recyclable photocatalysts of Ni-Cu-Zn ferrite@SiO $\mathrm{Si}_{2} @ \mathrm{TiO}_{2} @ \mathrm{Ag}$ and their photocatalytic activities. J. Photochem. Photobiol. A Chem. 2017, 334, 74-85. [CrossRef]

93. Somiya, S.; Roy, R. Hydrothermal synthesis of fine oxide powders. Bull. Mater. Sci. 2000, 23, 453-460. [CrossRef]

94. Wu, G.S.; Wang, J.P.; Thomas, D.F.; Chen, A.C. Synthesis of F-doped flower-like $\mathrm{TiO}_{2}$ nanostructures with high photoelectrochemical activity. Langmuir 2008, 24, 3503-3509. [CrossRef]

95. Jing, L.Q.; Xu, Y.G.; Huang, S.Q.; Xie, M.; He, M.Q.; Xu, H.; Li, H.M.; Zhang, Q. Novel magnetic $\mathrm{CoFe}_{2} \mathrm{O}_{4} / \mathrm{Ag} / \mathrm{Ag}_{3} \mathrm{VO}_{4}$ composites: Highly efficient visible light photocatalytic and antibacterial activity. Appl. Catal. B-Environ. 2016, 199, 11-22. [CrossRef]

96. Cho, I.S.; Lee, C.H.; Feng, Y.Z.; Logar, M.; Rao, P.M.; Cai, L.L.; Kim, D.R.; Sinclair, R.; Zheng, X.L. Codoping titanium dioxide nanowires with tungsten and carbon for enhanced photoelectrochemical performance. Nat. Commun. 2013, 4, 8. [CrossRef]

97. Yang, D.J.; Liu, H.W.; Zheng, Z.F.; Yuan, Y.; Zhao, J.C.; Waclawik, E.R.; Ke, X.B.; Zhu, H.Y. An Efficient Photocatalyst Structure: $\mathrm{TiO}_{2}$ (B) Nanofibers with a Shell of Anatase Nanocrystals. J. Am. Chem. Soc. 2009, 131, 17885-17893. [CrossRef]

98. Zhang, Y.; Park, S.J. Bimetallic AuPd alloy nanoparticles deposited on $\mathrm{MoO}_{3}$ nanowires for enhanced visible-light driven trichloroethylene degradation. J. Catal. 2018, 361, 238-247. [CrossRef]

99. Li, D.; Xia, Y.N. Electrospinning of nanofibers: Reinventing the wheel? Adv. Mater. 2004, 16, 1151-1170. [CrossRef]

100. Greiner, A.; Wendorff, J.H. Electrospinning: A fascinating method for the preparation of ultrathin fibres. Angew. Chem. Int. Edit. 2007, 46, 5670-5703. [CrossRef]

101. Reneker, D.H.; Chun, I. Nanometre diameter fibres of polymer, produced by electrospinning. Nanotechnology 1996, 7, 216-223. [CrossRef]

102. Wu, X.H.; Si, Y.; Yu, J.Y.; Ding, B. Titania-based electrospun nanofibrous materials: A new model for organic pollutants degradation. MRS Commun. 2018, 8, 765-781. [CrossRef]

103. Agarwal, S.; Greiner, A.; Wendorff, J.H. Functional materials by electrospinning of polymers. Prog. Polym. Sci. 2013, 38, 963-991. [CrossRef] 
104. Zhang, R.Z.; Wang, X.Q.; Song, J.; Si, Y.; Zhuang, X.M.; Yu, J.Y.; Ding, B. In situ synthesis of flexible hierarchical $\mathrm{TiO}_{2}$ nanofibrous membranes with enhanced photocatalytic activity. J. Mater. Chem. A 2015, 3, 22136-22144. [CrossRef]

105. Panthi, G.; Park, M.; Kim, H.Y.; Park, S.J. Electrospun Ag-CoF doped PU nanofibers: Effective visible light catalyst for photodegradation of organic dyes. Macromol. Res. 2014, 22, 895-900. [CrossRef]

106. Panthi, G.; Park, M.; Park, S.J.; Kim, H.Y. PAN Electrospun nanofibers reinforced with $\mathrm{Ag}_{2} \mathrm{CO}_{3}$ nanoparticles: Highly efficient visible light photocatalyst for photodegradation of organic contaminants in waste water. Macromol. Res. 2015, 23, 149-155. [CrossRef]

107. Saud, P.S.; Pant, B.; Park, M.; Chae, S.H.; Park, S.J.; El-Newehy, M.; Al-Deyab, S.S.; Kim, H.Y. Preparation and photocatalytic activity of fly ash incorporated $\mathrm{TiO}_{2}$ nanofibers for effective removal of organic pollutants. Ceram. Int. 2015, 41, 1771-1777. [CrossRef]

108. Seong, D.B.; Son, Y.R.; Park, S.J. A study of reduced graphene oxide/leaf-shaped $\mathrm{TiO}_{2}$ nanofibers for enhanced photocatalytic performance via electrospinning. J. Solid State Chem. 2018, 266, 196-204. [CrossRef]

109. Zhang, Y.F.; Park, M.; Kim, H.Y.; Ding, B.; Park, S.J. In-situ synthesis of nanofibers with various ratios of $\mathrm{BiOCl}_{\mathrm{x}} / \mathrm{BiOBr}_{\mathrm{y}} / \mathrm{BiOI}_{\mathrm{z}}$ for effective trichloroethylene photocatalytic degradation. Appl. Surf. Sci. 2016, 384, 192-199. [CrossRef]

110. Zhang, D.Q.; Li, G.S.; Li, H.X.; Lu, Y.F. The development of better photocatalysts through composition- and structure-engineering. Chem. Asian J. 2013, 8, 26-40. [CrossRef]

111. Chen, F.T.; Fang, P.F.; Gao, Y.P.; Liu, Z.; Liu, Y.; Dai, Y.Q. Effective removal of high-chroma crystal violet over $\mathrm{TiO}_{2}$-based nanosheet by adsorption-photocatalytic degradation. Chem. Eng. J. 2012, 204, 107-113. [CrossRef]

112. Ma, X.D.; Jiang, D.L.; Xiao, P.; Jin, Y.; Meng, S.C.; Chen, M. 2D/2D heterojunctions of $\mathrm{WO}_{3}$ nanosheet $/ \mathrm{K}^{+} \mathrm{Ca}_{2} \mathrm{Nb}_{3} \mathrm{O}_{10}{ }^{-}$ultrathin nanosheet with improved charge separation efficiency for significantly boosting photocatalysis. Catal. Sci. Technol. 2017, 7, 3481-3491. [CrossRef]

113. Wang, C.Y.; Zhang, X.; Song, X.N.; Wang, W.K.; Yu, H.Q. Novel $\mathrm{Bi}_{12} \mathrm{O}_{15} \mathrm{Cl}_{6}$ photocatalyst for the degradation of bisphenol a under visible-light irradiation. ACS Appl. Mater. Interfaces 2016, 8, 5320-5326. [CrossRef]

114. Zhang, Y.F.; Park, S.J. Fabrication and characterization of flower-like BiOI/Pt heterostructure with enhanced photocatalytic activity under visible light irradiation. J. Solid State Chem. 2017, 253, 421-429. [CrossRef]

115. Jiang, W.J.; Zhu, Y.F.; Zhu, G.X.; Zhang, Z.J.; Chen, X.J.; Yao, W.Q. Three-dimensional photocatalysts with a network structure. J. Mater. Chem. A 2017, 5, 5661-5679. [CrossRef]

116. Wan, W.C.; Zhang, R.Y.; Ma, M.Z.; Zhou, Y. Monolithic aerogel photocatalysts: A review. J. Mater. Chem. A 2018, 6, 754-775. [CrossRef]

117. Pierre, A.C.; Pajonk, G.M. Chemistry of aerogels and their applications. Chem. Rev. 2002, 102, $4243-4265$. [CrossRef]

118. Dagan, G.; Tomkiewicz, M. Titanium dioxide aerogels for photocatalytic decontamination of aquatic environments. J. Phys. Chem. 1993, 97, 12651-12655. [CrossRef]

119. Heiligtag, F.J.; Rossell, M.D.; Suess, M.J.; Niederberger, M. Template-free co-assembly of preformed Au and $\mathrm{TiO}_{2}$ nanoparticles into multicomponent 3D aerogels. J. Mater. Chem. 2011, 21, 16893-16899. [CrossRef]

120. Kailasam, K.; Epping, J.D.; Thomas, A.; Losse, S.; Junge, H. Mesoporous carbon nitride-silica composites by a combined sol-gel/thermal condensation approach and their application as photocatalysts. Energy Environ. Sci. 2011, 4, 4668-4674. [CrossRef]

121. Li, Z.D.; Wang, H.L.; Wei, X.N.; Liu, X.Y.; Yang, Y.F.; Jiang, W.F. Preparation and photocatalytic performance of magnetic $\mathrm{Fe}_{3} \mathrm{O}_{4} @ \mathrm{TiO}_{2}$ core-shell microspheres supported by silica aerogels from industrial fly ash. J. Alloys Compd. 2016, 659, 240-247. [CrossRef]

122. Jiang, W.J.; Liu, Y.F.; Wang, J.; Zhang, M.; Luo, W.J.; Zhu, Y.F. Separation-free polyaniline $/ \mathrm{TiO}_{2} 3 \mathrm{D}$ hydrogel with high photocatalytic activity. Adv. Mater. Interfaces 2016, 3, 1500502. [CrossRef]

(C) 2019 by the authors. Licensee MDPI, Basel, Switzerland. This article is an open access article distributed under the terms and conditions of the Creative Commons Attribution (CC BY) license (http:/ / creativecommons.org/licenses/by/4.0/). 